\title{
Domestic violence sentencing: coefficient to a natural process that already reduces recidivism simply as a function of aging
}

\author{
Eric L Nelson
}

\begin{abstract}
Background: Research on domestic violence (DV) sentencing, post-conviction, has mostly focused on incarceration and re-education programs, ignoring more than a dozen other components of the criminal sentence. Therefore, little is known, overall, about the breadth of DV sentencing, antecedents that may shape the content of the sentence, and a possible relationship between the criminal sentence and a theorized natural process believed to significantly reduce DV recidivism simply as a function of aging.

Results: Data from this empirical study $(N=1,810)$ reveals rates of female DV recidivism decrease by about $2.56 \%$ per year, between ages 22-61, and males by about 3.13\% per year between ages 28-60. These data closely match Federal Bureau of Investigation rates for recidivism, by age and sex, for violent crime in general. The study also identified 16 sentencing components used by judges in DV cases. Logistic regression on data from a randomly selected subset $(n=366)$, using the 16 sentencing components as dichotomous outcomes, regressed against 49 antecedent variables, illuminated a number of factors that have a significant relationship with the content of individual DV sentences, including many extra investigative actions that police officers can operationalize when investigating DV crime.

Conclusion: Confirmation of a natural process that diminishes rates of DV recidivism as a function of aging demonstrates the need to factor this effect into any equation designed to assess the effectiveness of DV sentencing, or re-education/treatment programs upon rates of recidivism. It also confirms that the natural process is an important part of the milieu in which the criminal sentence is operationalized. The results also demonstrate the need for police to thoroughly investigate all DV crime, and to list multiple charges whenever the facts support doing so, because doing so significantly raises rates of inclusion of several sentencing components.
\end{abstract}

Keyword: Domestic violence; Sentencing; Police; Age; Recidivism

\section{Background}

In western systems of justice criminal defendants (people accused of crimes by the State) face the potential of trial, where they risk being found guilty on all charges and having the full set of sentencing options imposed upon them such as incarceration, fines, probation, and an order to attend some form of treatment, and so forth. The criminal sentence is an assembly of individual orders that may include punishment, rehabilitation, compensation, and conduct requirements. Arguably, the various sentencing

Correspondence: elnelson@ucdavis.edu

Criminology \& Criminal Justice (Individual Program), University of California, c/o Office of Graduate Studies, 1 Shields Avenue, Davis, California 95616, USA components share a common goal: Reduction of the likelihood of criminal re-offending.

Many defendants may choose to negotiate a reduced sentence in exchange for a guilty plea to one or more of the crimes they are charged with having committed. Alschuler describes plea bargaining, what this type of negotiation is called, as "the exchange of official concessions for a defendant's act of self-conviction" (Alschuler 1979). In the United States $93-95 \%$ of all criminal cases in local and state courts, and $97 \%$ of all federal prosecutions are resolved through negotiation and not criminal trial (Bureau of Justice Statistics 2008; Sourcebook of Criminal Justice Statistics, 2002, 2004; United States Courts $2011^{\mathrm{a}}$ ). Once the defendant pleads guilty or is found guilty at trial, a sentence is imposed. 
Components of the domestic violence criminal sentence With regard to domestic violence (DV), little scholarly attention has been paid to the breadth of sentencing options from which a judge can select, when crafting a unique order for a particular convicted person. Typically when scholarly work examines DV sentencing they report on only two types of data: Length of jail terms e.g., (Chiricos \& Waldo, 1975; Kingsnorth et al. 1998; Steffensmeier et al. 1998; Ulmer \& Johnson, 2006; Wooldredge \& Thistlethwaite 2006) and efficacy of treatment programs e.g. (National Institute of Justice, 2003a, 2003b; Corvo et al. 2008; Dunford, 2000; Dutton, 2005; Dutton \& Corvo 2006; Babcock et al. 2004; Whitaker, Baker, \& Arias, 2007). Failing to examine the full range of sentencing options may have created an incomplete view of the manner in which a person convicted of domestic violence crime is punished, rehabilitated, the compensation they must pay, and the conduct requirements they must fulfill.

A detailed search of the literature yielded only three studies that describe the breadth of sentencing components from which a judge can choose for any type of criminal case. Two studies summarize a range of sentencing components for a wide variety of crime (Illinois Criminal Justice Information Authority 2002; and California Research Bureau, 2003), and one study describes a set of sentencing options for violation of a domestic violence restraining order (DVRO), (Diviney et al. 2008). No studies describing a full set of sentencing options for domestic violence crime was located. A summary of the sentencing options that were found is seen below in Table 1.

As the contents of the table demonstrate, there are a wide variety of options from which a judge can select when creating a sentencing order, much more than is apparent from reading typical articles on domestic violence sentencing. However, even though judges are presented with many choices about what to include, they are not always free to craft a sentencing order they feel is most appropriate. That is because some components of the domestic violence criminal sentence are mandated by law. For example, in California the sentence is supposed to include a minimum of 36 months probation, a conduct order with stay away provisions, a minimum of \$400 USD fine, mandatory attendance of a re-education program, and a requirement to perform community service (California Penal Code \$1203.097). However, judges in California often deviate from these mandates, by not including all of the required components (California State Attorney General, 2005).

Because so little is known about the breadth of domestic violence sentencing, the first task of the present study is to help fill that hole in the literature by identifying a full set of sentencing options available to judges. In
Table 1 General sentencing components identified in the scholarly literature, sorted according to percentage of use

\begin{tabular}{|c|c|c|c|}
\hline \multirow[t]{5}{*}{ Variables } & \multicolumn{3}{|c|}{ Source, size of study, type of study } \\
\hline & ICJIA 2000 & Diviney et al. 2008 & CRB 2003 \\
\hline & $(\mathrm{N}=3,364)$ & $(N=136)$ & $(\mathrm{N}=451,000)$ \\
\hline & General Crime & DVRO Violation & General Crime \\
\hline & $\%$ Inclusion & $\%$ Inclusion & (\% Not Given) \\
\hline Probation & & 72 & \\
\hline Supervision fee & 70 & & \\
\hline Court costs & 52 & & \\
\hline $\begin{array}{l}\text { Restitution and } \\
\text { fines }\end{array}$ & 52 & 39 & * \\
\hline $\begin{array}{l}\text { Substance abuse } \\
\text { treatment }\end{array}$ & 50 & 11 & * \\
\hline Incarceration & & 49 & * \\
\hline Other treatment & & 34 & \\
\hline
\end{tabular}

Drug monitoring 28

Batterer education

program

Community service 22

Anger management

class

Mental health

28

treatment

Surrender firearms

Electronic

monitoring

Couples counseling

Sex offender

treatment

Intensive

supervision

Electronic

monitoring

Day reporting

22

09

$09-2$

House arrest

Halfway house

placement

Note: * Denotes usage.

addition, there is another aspect of DV sentencing that must be considered if one is to fairly evaluate the framework within which the DV sentence is operationalized, post-criminal conviction.

\section{Evaluating the natural framework within which the domestic violence sentence is imposed}

The age/crime relationship has been assumed to be true by many criminologists (Hirschi and Gottfredson, 1983; Blonigen $2010^{\mathrm{b}}$ ), though other factors may also explain crime without reference to age (Hirschi and Gottfredson 1983). Farrington's masterful disambiguation of key factors in the age/crime discussion (Farrington 1986) lead 
him to argue for a concurrence of three effects: Aging, a period effect influenced by economic and other factors, and also a cohort effect based upon year of birth. However, Farrington's dismissal of age as a cause of crime is unconvincing when one considers the consistent pattern of distribution seen across a wide variety of crime, when plotted for age. Consistent replication is a strong marker of established relationships. Yet, at the same time Farrington's point that age probably isn't a cause of crime, but rather a measure of a complicated set of underlying theoretical construct is well taken and may be right. However, for lack of a better descriptor we continue to use "age", with Farrington's point duly noted.

An example of the aging effect can be seen in Figure 1. Using Federal Bureau of Investigation data for a variety of violence crimes (Federal Bureau of Investigation 2003, p. 6) ${ }^{\mathrm{C}}$ within-group rates of violence, by sex, were plotted for age. The general shape of this plot is consistent with those seen in other publications, including (Hirschi and Gottfredson 1983), (Farrington 1986), and (Blonigen 2010).

As the graph demonstrates, within-group rates of violence by females across a span of violent crimes achieves maxima around age 21, and thereafter decreases to slightly above zero by age 60 . Because the slope is relatively linear, the rate of change is approximately the same each year. Accordingly, we can calculate a rate of change using the algorithm seen in Equation one (1).

$$
\text { Rate }=(1 / \mathrm{n}) * 10^{2}
$$

where $n$ is the number of years between apogee and the point where the rate approaches zero. In the case of general female violence, the point of inflection is about age 21, and the slope approaches zero at about age 60; thus, $\mathrm{n}=39$, and we calculate Rate $=(1 / 39) * 10^{2}=2.5641$ per year. Thus, the natural process of violence potential reduction for females is seen to be slightly more than two and half percent, per year. Male violence achieves maxima at about age 18, decreasing to slightly above zero by age 60 , at a yearly rate of reduction of about $2.38 \%$.

The age/violence potential effect (AVPE) demonstrated in Figure 1 uses aggregated data drawn from a number of different types of violent crime; thus, its specific applicability to domestic violence crime is uncertain. It seems reasonable to suspect that the AVPE would also describe domestic violence crime; however, to date this proposition has not been tested sufficiently. Pioneering work by (Straus et al. 1980:Chart 11, p. 141) did examine rates of domestic violence in four age groups: 30 and under, 31-50, 51-65, and 65 and over. The results showed a steady diminishment of violence potential across the four groups, as age increased. Though a trend is seen in their data, the use of large age categories and the failure to distinguish between males and females prevents more nuanced analysis. In another study, three years of longitudinal data demonstrated a similar trend (O’Leary et al. 1989).

Should the natural operation of the age/violence potential effect be confirmed as also describing the natural reduction of DV recidivism according to age, it would thereafter become necessary to re-conceptualize our understanding of DV sentencing and DV recidivism in order to account for the natural process. Under these

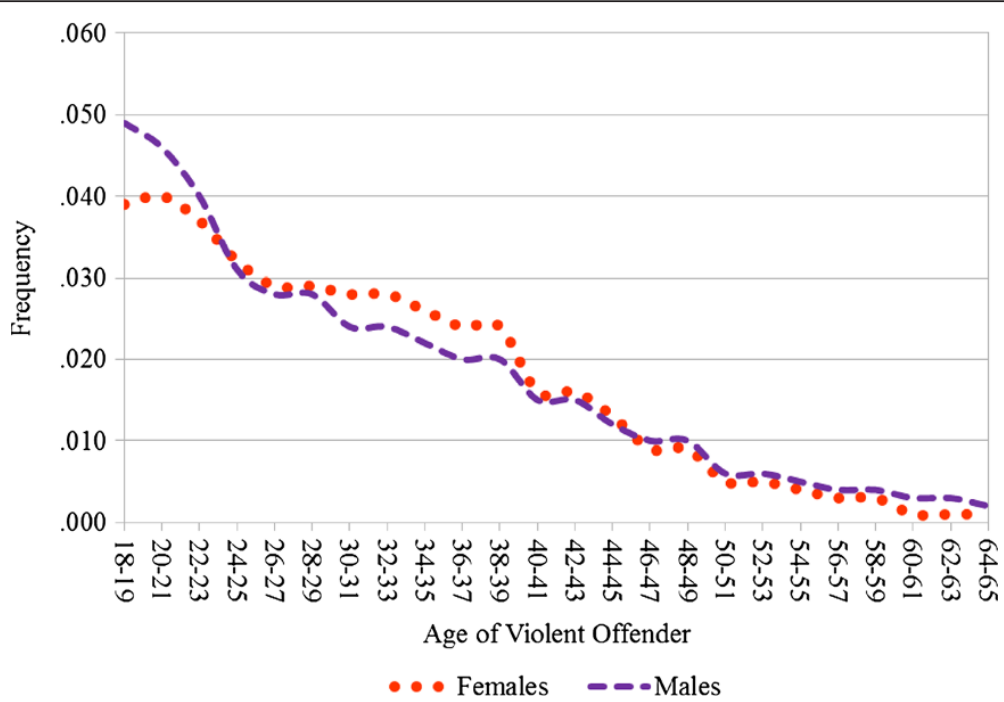

Figure 1 Comparison of within group arrest frequencies, by sex and age group, for violent criminal behavior. Data source: (Federal Bureau of Investigation 2003:6). 
theorized circumstances imposition of a DV criminal sentence, post-conviction, could therefore be seen as the introduction of an artificial coefficient to a natural equation. In other words:

$$
\mathrm{y}_{\mathrm{x}}=\mathrm{y}_{0} *(1-\mathrm{xa})
$$

would become

$$
\mathrm{y}_{\mathrm{x}}=\mathrm{y}_{0} *(1-\mathrm{xa}) * \mathrm{~b}_{\mathrm{x}}
$$

where $y_{x}$ is the within-group rate of violence for year $x$; $y_{0}$ is the within-group rate of violence at the point of inflection; $x$ is a count of whole years past the point of inflection; $a$ is the within-group rate of linear change between maxima and minima as calculated using Eq. 1; and $b$ is the coefficient of change induced by the sum of the effects of individual sentencing components. ${ }^{\mathrm{d}}$ Investigating for the possible operation of a DV-AVPE is the second purpose of the present study.

\section{Summary}

Little is known about the breadth of domestic violence sentencing components, or the natural process that may represent an important part of the milieu in which the DV criminal sentence is operationalized. The domestic violence criminal sentence may actually represent an attempt to apply pressure to the natural slope in order to significantly increase its negativity. Using empirical data the present study aims to correct a vacuum in the literature regarding the breadth of potential content of the DV criminal sentence, many of their significant antecedents, and to examine for the operation of a domestic violence age/violence potential effect.

\section{Hypothesis}

The null hypothesis asserts that within and between group rates of domestic violence, according to sex and age, will not be similar to those measured in the general population for all types of violence combined, as reported by the FBI and seen in Figure 1. The alternative explanation asserts the rates will, upon inspection, ${ }^{\text {e be }}$ seen to be similar.

\section{Method}

\section{Source of data}

The author was granted access to the computer system of a mid-sized police agency in California, and also the prosecutor's office for the county. The purpose of the access was to allow direct reading of police reports and prosecutor files so that individual police investigations of domestic violence could be followed from "cradle to grave", meaning from the moment a police officer was dispatched to investigate, until the time that prosecutors either rejected an investigation, refusing to file criminal charges, or until filed cases were concluded. In the year 2008 the police agency produced $\mathrm{N}=1,810$ domestic violence investigation reports, each assigned a unique number. Those numbers were used to match prosecutor files with police investigation reports. Because the records of both agencies are computerized, problems locating files were not encountered. Data was collected over a 2.5 year period.

A total of 16 types of data were collected for all cases, including demographics of the suspect(s) and victim(s), and different crime codes. An additional 242 types of data were collected on $n=366$ randomly selected investigations. These data included important dates, so that time periods could be measured; types of witnesses, and counts of witnesses; charges recommended by police, charges filed by prosecutors, and charges defendants were convicted of; reasons police investigations were rejected by prosecutors, and so forth. The results are being reported across several journal articles.

Raw data was entered into a password protected spreadsheet, comprised of 88,572 data cells. The spreadsheet was subdivided into a number of tables and was used for a variety of calculations including mean, standard deviation, $\mathrm{t}$ and $\mathrm{z}$ test significance comparisons for means and ratios, creation of pivot tables, and so forth. The raw data table was imported into Stata/IC 10.0 for statistical assessment. Stata was used to conduct individual and model OLS and logistic regression, and to perform survival and hazard analysis.

\section{Explanation of style used to present statistical results}

In traditional subscription journals the manner in which statistical results are presented may not be understandable to non-scholars. For example, Beta values resulting from logistic regression are probably not easily understood. This is true because Beta values must be further processed into odds ratios, or percentage change values in order to make useful sense of them.

One must question to whom open source articles such as those published in Crime Science are addressed, because this should have a bearing upon the manner in which statistical results are presented. If research scholars are writing to fellows, as is done in subscription-based journals, there is no reason to change traditional methods of data presentation. However, open source journals scholars are writing to a larger audience that also includes junior high and high school students and teachers, working professionals who may not have access to university library journal subscriptions, journalists and other nonacademic professional researchers, and indeed to all the interested people of the world who take the time to download a particular open source article and read it, in addition to an academic audience. 
Therefore, it is held that scholars who publish in open source journals should reconsider how their statistical results are presented. The traditional manner in which results of logistic regression are presented provides a case-in-point example. The non-academic public might make use of these outcome values if only they could understand what a Beta score means.

It is believed that research scholars publishing in open source journals should assume an intelligent, capable, and curious world reader who can make practical use of their empirical findings, so long as results are made understandable to all. The first step towards operationalizing that goal has already been taken: Open source journals such as Crime Science have been established. However, that is not felt to be enough. Open source scholars must take upon themselves the burden of presenting understandable data that is accessible to a curious world, whenever possible. Following that mandate then, and continuing to use Beta values as an example, we can convert beta values into a form that is more accessible to world readers. Equation 4 displays the algorithm for doing so.

$$
\text { Pct Change }=\left(\exp ^{\beta}-1\right) * 10^{2}
$$

An example should make this point clear. Using other data from a prior paper (Nelson, 2013) we can logistically regress the continuous variable "pdcsum" on the dichotomous outcome "DAFile" g. The antecedent variable is a count of how many charges are recommended in the written report of a first responding police officer (FRPO) who investigated a particular domestic violence crime, (e.g., one charge is listed, or two, or three, and so forth). The outcome is coded one (1) if the prosecutor filed a criminal case, and zero (0) if not. Logistic regression produces the following result: $\beta=1.292882(\mathrm{n}=366$, $\mathrm{X}^{2}=40.92, \mathrm{p}<.0000$, pseudo $\left.\mathrm{R}^{2}=.0918 ; \mathrm{z}=5.10, \mathrm{p}<.0000\right)$.

One must ask: Could a curious and intelligent nonacademic really make sense of the outcome $\beta=1.292882$ ? What does the Beta value tell a police officer in Singapore, a prosecutor in Malaysia, a high school student in Sweden, or a judge in Sudan? To make this outcome useful to a world readership it must be converted to an understandable value. Accordingly, using the fourth equation, we calculate the percentage change value to be $264 \%$. That is a number the world can work with, so long as it is interpreted correctly. In this case that explanation would be "For each additional charge listed in the FRPOs written report, there is a $264 \%$ greater chance that the prosecutor will file a criminal case against the suspect identified in the police report."

Acting to expand the accessibility of the empirical findings of the present study, Beta and percentage values are presented side-by-side in the results tables. Scholars may use the $\beta$ value, and world readers may use the percentage change value.

\section{Dependent variables}

Direct examination of prosecutor files demonstrated that 16 sentencing components are available to judges for possible inclusion in the sentencing order. Each outcome was separately recorded as a dichotomous variable where $1=$ included and $0=$ not included.

\section{Independent variables}

Forty nine explanatory variables, a subset of the larger data pool, were evaluated for their potential relationship to the 16 sentencing outcomes. Of those, eight measure police actions; one is a word count of the first responding police officer's written report; two measure aspects of charges that are filed by the prosecutor; $^{\text {h }}$ four characterize statements and actions of the suspect when interacting with police; eighteen measure suspect and victim demographics; nine measure characteristics of witnesses and their statements to police; and seven measure the types of charges that a defendant is convicted of. Among these, seven are continuous variables, and forty two are dichotomous. A list of these variables is seen in Table 2.

\section{Analysis of the data}

Because all of the outcomes are dichotomous variables, logistic regression is the appropriate choice for statistical analysis. The outcomes are seen in the results tables. Each explanatory variable was regressed individually on all outcomes, thus producing a results spreadsheet comprised of 784 individual cells. Variables that were significant for a particular outcome were regressed again, en masse, for that outcome, and then a third time in a bestfit model. Results for each stage of regression are presented in individual tables.

\section{Criteria for establishing antecedent variable significance}

Paying less attention to explanatory variables that show diminished power when assessed in a model, rather than alone, might be a mistaken practice. Scholars cannot rule out the possibility that the influence of a particular variable may continue to be expressed, albeit through another outcome with which the variable is collinear; after all, something has to explain how the explanatory power of some independent variables increase when regressed in parallel with others, in a model.

Probably no experiment can ever be designed to test whether this is true, for certain, or not; however, borrowing from physics the assumption of a form of conservation is not believed to be unreasonable; and, ultimately, criminologists and social science scholars must guess about such things anyway. Because guesses about how 


\section{Table 2 Antecedent variables: abbreviations \&} explanations

Abbreviation
EPO Obtained
Photos Req. or Obtained
Susp. Was Arrested
$\geq 1$ Juv. Victims
PD Inv. Time < 240 hrs.
Charge Count - Police
Charge Count - Filed
Charge Count - Conv.
Reasons Count - Case Rej.

5th Amend. Invoked

Susp. Admits Guilt

Susp. Claims Mutual

Susp. Denies Guilt

Witness Sum

Witnesses Interviewed

No Witnesses

Juv. Wit. Not Related

Juv. Witness Related

Juv. Witness Rel. Unk.

Adult Wit. Not Related

Adult Witness Related

Adult Wit. Rel. Unk.

Wit. Not Classified

Witnesses Favorable

Explanation

An Emergency Protective Order (EPO) was obtained.

Photographs were requested or obtained.

The suspect was located and arrested by police.

One or more juveniles listed as a victim in the police report.

The police report was delivered to the prosecutor's office in 240 hours or less.

Count: The number of charges recommended by police.

Count: The number of charges filed by prosecutors.

Count: The number of charges the defendant was convicted of.

The number of reasons given by prosecutors for rejecting an investigation.

The suspect, when questioned by police, invoked the 5th Amendment.

The suspect, when questioned by police, admitted committing one or more crimes.

The suspect, when questioned by police, claimed the DV was mutual combat.

The suspect, when questioned by police, denied committing one or more crimes.

The number of witnesses listed in police report (not necessarily interviewed).

The number of witnesses interviewed by police.

No witnesses were interviewed by police.

One or more witnesses are juveniles not related to the suspect.

One or more witnesses are juveniles related to the suspect.

One or more witnesses are juveniles whose relationship to the suspect is not clarified.

One or more adult witnesses are not related to the suspect.

One or more adult witnesses are related to the suspect.

One or more witnesses are adults whose relationship to the suspect is not clarified.

There are one or more other types of witness not classified in any other category.
Table 2 Antecedent variables: abbreviations \& explanations (Continued)

\begin{tabular}{|c|c|}
\hline & $\begin{array}{l}\text { On balance the witness statements are } \\
\text { favorable towards the suspect. }\end{array}$ \\
\hline Mult. Chgs. - Conv. & $\begin{array}{l}\text { The defendant was convicted of one or } \\
\text { more charges (all types combined). }\end{array}$ \\
\hline Conv. $\geq 1$ Misd. DV & $\begin{array}{l}\text { The defendant was convicted of one or } \\
\text { more misdemeanor DV crimes. }\end{array}$ \\
\hline Conv. $\geq 1$ Fel. DV & $\begin{array}{l}\text { The defendant was convicted of one or } \\
\text { more felony DV crimes. }\end{array}$ \\
\hline Conv. $\geq 1$ Violation DVRO & $\begin{array}{l}\text { The defendant was convicted of one or } \\
\text { more violations of a DV restraining order. }\end{array}$ \\
\hline Conv. $\geq 1$ Non-DV Crime & $\begin{array}{l}\text { The defendant was convicted of one or } \\
\text { more non-DV charges. }\end{array}$ \\
\hline Conv. $\geq 1$ Child Endanger. & $\begin{array}{l}\text { The defendant was convicted of one or } \\
\text { more child endangerment charges. }\end{array}$ \\
\hline Word Count - Police Report & $\begin{array}{l}\text { The number of words in the police } \\
\text { report. }\end{array}$ \\
\hline Susp. Sex: Male & The suspect's biological sex is male. \\
\hline Susp. Sex: Female & The suspect's biological sex is female. \\
\hline Susp. Age & $\begin{array}{l}\text { The suspect's age on the day the police } \\
\text { report was written. }\end{array}$ \\
\hline Susp. Race: White & The suspect is White. \\
\hline Susp. Race: Black & The suspect is Black. \\
\hline Susp. Race: Hispanic & The suspect is Hispanic. \\
\hline Susp. Race: Asian & The suspect is Asian. \\
\hline Susp. Race: Not White & $\begin{array}{l}\text { The suspect is not White (Black + } \\
\text { Hispanic + Asian). }\end{array}$ \\
\hline Susp. Race: Not Black & $\begin{array}{l}\text { The suspect is not Black (White + } \\
\text { Hispanic + Asian) }\end{array}$ \\
\hline Vict. Sex: Male & The victim's biological sex is male. \\
\hline Vict. Sex: Female & The victim's biological sex is female. \\
\hline Vict. Age & $\begin{array}{l}\text { The victim's age on the day the police } \\
\text { report was written. }\end{array}$ \\
\hline Vict. Race: White & The victim is White. \\
\hline Vict. Race: Black & The victim is Black. \\
\hline Vict. Race: Hispanic & The victim is Hispanic. \\
\hline Vict. Race: Asian & The victim is Asian. \\
\hline Vict. Race: Not White & $\begin{array}{l}\text { The victim is not White (Black + } \\
\text { Hispanic + Asian). }\end{array}$ \\
\hline Vict. Race: Not Black & $\begin{array}{l}\text { The victim is not Black (White + } \\
\text { Hispanic + Asian). }\end{array}$ \\
\hline
\end{tabular}

to interpret criminological findings can affect criminal justice procedure, and public policy, prudence would seem to suggest that one should be cautious about rejecting any variable that demonstrates significance upon individual regression. That caution drives this paper; and thus, variables that perform significantly well, individually, are viewed as important indicia of how the criminal justice response to domestic violence crime is shaped with regard to post-conviction sentencing, even as the measure of the pressure of their 
influence is elusive, all this being done while remaining aware of the possible operation of collinearity. By providing probability levels for all outcomes, in the results, readers can evaluate the results within their own range of acceptance. It is for that reason that the full data tables, and not merely summaries are provided in the appendix.

\section{Justification for the assumption of cause}

A causal relationship is assumed between police-controlled variables and outcomes, for several reasons. First, with one exception, all of the explanatory variables have a fixed value before prosecutors become involved with the case. ${ }^{i}$ Second, there no feedback system by which prosecutors can influence decisions taken by police, when investigating domestic violence crime, in situ, nor can they change victim, suspect, witness, and child-victim demographics. Prosecutors do not ride in police cars in order to advise police officers how to do their job. Third, the uni-directional, linear nature of the criminal justice system is such that the work of the first responding police officer is entirely completed, and memorialized in a written report before the work of prosecutors begin. Prosecutors work for a different government agency, in a different location. If they have contact with police, it is after reading an officer's report. Thus, there are no feedback loops of influence from prosecution to officer, for specific investigations. Finally, a causal assumption is felt to be parsimonious: It makes sense to believe that the quality of the police investigation significantly influences prosecutorial outcomes. It should be noted that some of the characteristics of a case are not under the control of police, such as demographics. Variables that may be under police control include: The decision whether to seek an emergency protective order, whether to take photographs, whether to make an effort to locate additional witnesses, whether to make an arrest, whether to list more than one charge, and whether to complete the investigation and write a report the same day, or not.

\section{Limitations}

These data describe a particular criminal justice system in a specific city in California; as such, they may not fully describe the sentencing processes in other criminal justice systems in other places. Also, there is potential for authorial bias, as the author is a former police officer who specialized in domestic violence investigation at the first responder level. However, because the data is quantitative in nature, it is felt that the potential to insert bias was naturally kept to a minimum by the non-interpretive, numerical nature of most of the data; such as, either a secondary charge of vandalism was included, or not, and so on. There is a risk of both types of interpretive error when examining the results of individual variable regression tables, due to the potential operation of collinearity. However, that argument can be turned around. The reduced number of variables that show significance in modeling may actually be demonstrating a parasitic collinear effect, by drawing strength and significance from donor variables that were excluded because they show diminished power and significance when regressed in parallel. Thus, caution is indicated when interpreting both individual or model results.

Another potential weakness is the fact that not all domestic violence comes to the attention of police; so, it is unknown how well data acquired from police records actually describes rates of domestic violence in general. In this study, that concern only applies to the measure of the DV age-violence potential effect (DV-AVPE), because the remainder of the data is not generalized to the full population. It is possible the AVPE rate to be measured for DV, by the present study, may differ from the unmeasured rate in the general population.

\section{Results}

In order to address the null hypothesis, the full data set $(\mathrm{N}=1,810)$ was used. Figure 2 contains a graph that presents within group frequencies, by sex and age group, for individuals who were identified as a domestic violence suspect in a written police report.

As the graph demonstrates, females and males show a similarly diminishing longitudinal pattern, though for males the peak of violence is delayed by about 6-7 years compared to females. The maxima for females is, essentially, identical to the one seen in Figure 1, it being about age 22 , with female violence decaying to zero at about age 61 . That rate of decline is $2.56 \%$ per year of age, making it identical to the one calculated from Figure 1. However, for domestically violent males, a bimodal maxima is seen, and it presentation is delayed about 10 years, to about age 28, when compared to the maxima for males seen in Figure 1. The end point for males is about the same in both figures, at age 60. The rate of change for males in Figure 2 is about 3.13\% per year of age. For both males and females, once the onset of the natural reduction in recidivism has begun, an approximately linear pattern is seen; however, at points within these data one sees some interesting points of localized inflection.

Because these data demonstrate a number of close similarities to those seen in Figure 1, including a very close parallel to the aggregated violence pattern, they are interpreted as fairly strong evidence that the ageviolence potential effect does, in fact, describe changes in the rates of domestic violence recidivism as well, according to age; therefore, the null hypothesis is rejected and the alternative explanation is accepted.

\section{Sentencing component frequencies}

Of the $n=366$ randomly selected investigations, $70 \%$ resulted in prosecution, and $44 \%$ resulted in criminal 


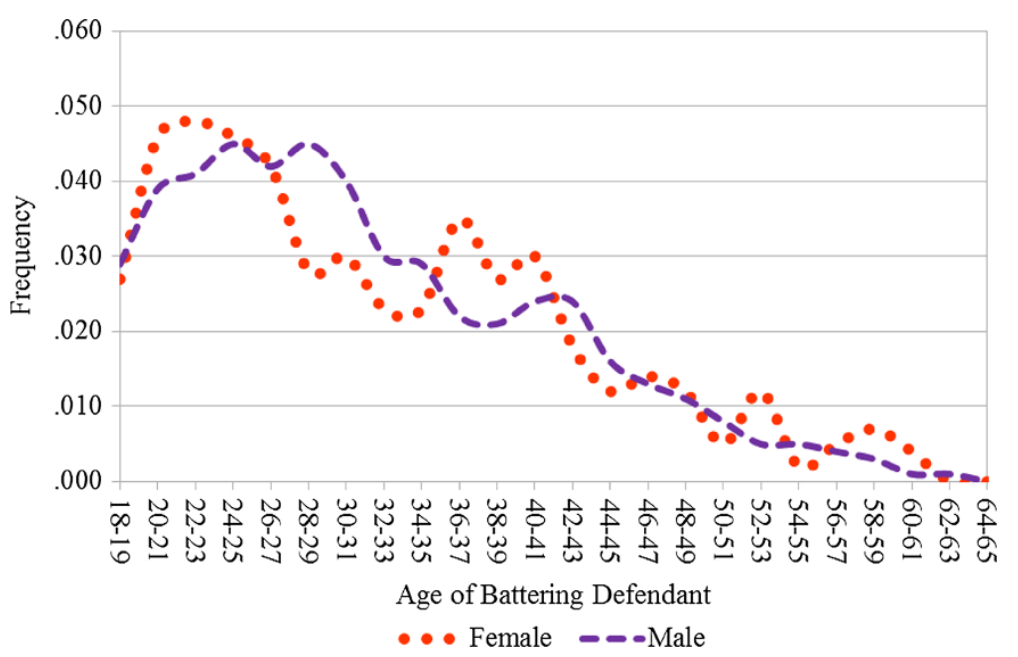

Figure 2 Comparison of within sex accusation frequencies, for domestic violence crime, by age group.

conviction. Though 16 sentencing components are available to judges, in actuality only 15 are used. The sentencing orders of defendants convicted of at least one domestic violence misdemeanor crime contain an average of 5.09 components $(\mathrm{sd}=3.28)$. Sentencing orders following a felony DV conviction contain an average of 5.22 components $(\mathrm{sd}=3.19)$. The full set of domestic violence sentencing options are described in Table 3, ordered by their frequency of use.

Probation is the most frequently used sentencing option, followed by confinement in jail. Nine sentencing options are used in at least one third of the cases, three in $15-30 \%$ of the cases, and the other four are not used very often. A wide variety of antecedent variables were found to have significant relationships with the various sentencing options. Those relationships are summarized in Figure 3, and their full details provided in Tables 4, 5, $6,7,8,9,10,11,12,13,14,15,16,17,18$.

\section{Relationships between explanatory variables and sentencing outcomes}

A wide variety of explanatory variables displayed significant interactions with multiple sentencing outcomes, from a high of $\mathrm{n}=17$ antecedents positively influencing the probability of being sentenced to jail, to a low of $n=2$ antecedents for being ordered to submit to random drug testing. The average number of significant individual interactions is 8.73 ( $\mathrm{sd}=4.68)$. A summary of these relationships can be seen in Figure 3 below. The full results can be seen in Tables 4, 5, 6, 7, 8, 9, 10, 11, 12, 13, 14, 15, 16, 17, 18.

Figure 3 is a visual rendition of the direction of the relationship between particular antecedents and outcomes they significantly influence, as well as the percentage of outcomes that are influenced in each direction. Positive relationships extend to the right and are denoted by black bars; whereas, inverse relationships extend to the left and are indicated by red bars. For example, we see that the choice of the suspect to invoke her/his 5th Amendment right significantly increases the likelihood about $60 \%$ of the sentencing options will be included in the order. Checking Tables 4, 5, 6, 7, 8, 9, 10, 11, 12, 13, $14,15,16,17,18$ we see this to be true, noting nine of them show a positive effect correlated to invoking the right to be silent $(9 / 16=56)$. Similarly we see that the age of the victim is inversely correlated to about $40 \%$ of

Table 3 Domestic violence sentencing variables and their percentage of use

\begin{tabular}{ll}
\hline Sentencing variables & Percent use \\
\hline Probation & 86 \\
Confinement in county jail & 82 \\
Pay a fine & 54 \\
Attend a 26 or 52 week domestic violence & 54 \\
re-education course. & \\
Stay away from the victim & 47 \\
Submit to warrantless searches by police or & 41 \\
probation officers & \\
Surrender all firearms, do not possess firearms & 39 \\
Obey all laws & 39 \\
Do not annoy, threaten, harass, or strike the victim & 35 \\
Pay restitution to the victim & 29 \\
Do not commit the same or similar offenses & 21 \\
Do not use drugs or alcohol & 15 \\
Harvey waiver & 5 \\
Confinement in state prison & 5 \\
Submit to drug testing without a warrant & 2 \\
Perform community service & 0 \\
\hline
\end{tabular}

Note: $\mathrm{n}=160$ convictions. 
the sentencing options $(6 / 16=38)$. In all but one case individual influence is unidirectional. Overall then, we can see from inspection of Figure 3 that nearly all antecedents are unambiguous about the direct and scope of their influence over potential sentencing components.

\section{Discussion}

The present study responds to two fundamental questions: "Does the aging process negatively influence rates of domestic violence recidivism?", and, "What is the identity and frequency of occurrence of individual DV sentencing components, and their antecedents of significance?" As the results of this study have demonstrated, the answers to these questions should be considered together because the two processes, aging and criminal sentences, act upon the same outcome. So long as one assumes each item of a DV criminal sentence is intended to reduce recidivism, then the aging process should be seen as an important part of the milieu within which the DV criminal sentence is operationalized.

\section{Making sense of the natural process}

Comparing the distribution pattern seen in Figure 2 to that in Figure 1 is seen to robustly answer the first empirical question in the affirmative. On six characteristics the distributions are seen to be quite similar: The direction of the slopes, the shape of the slopes as approximately linear, the location on the Y scale where maxima is achieved, the location on the $\mathrm{X}$ scale where frequency approaches zero, the period of decline between maxima and minima, and the percentage values for rates of change. Thus, it seems reasonable to accept the proposition that age is a strong predictor of domestic violence recidivism. Some interesting, previously unknown characteristics are also seen in the current data.

First is the delay of the male point of inflection for the crime of domestic violence. The data used to construct Figure 1 is an aggregate of five types of violence crime: Murder, manslaughter, forcible rape, robbery, and aggravated assault'. In Figure 1 inflection occurs around age 18; whereas domestic violence data shows male inflection delayed about 10 years (age 28), as shown in Figure 2. This is an interesting finding because between ages 18 and 28 male violence is decreasing across many types of violent crime even as it is still increasing across one other, domestic.

The second artifact is seen when individual sex patterns are compared. In Figure 2 females show two distinct periods of increasing violence-in the early and mid 20 's, and also the late $30^{\prime} \mathrm{s}$ and early $40^{\prime} \mathrm{s}$. There is a clear 8-10 year gap between them. Interestingly the male pattern seems to follow the female pattern, delayed by a few years, seen at four distinct locations on the graph. Twice as the female rate of violence increases the male rate increases thereafter; and, twice the female rate decreases with males following suit.

It is possible these patterns represent new findings regarding domestic violence recidivism. It is also possible these artifacts will flatten when larger data sets from multiple sources are analyzed. Since age records for DV 
Table 4 By antecedent, percentage change and odds of being sentenced to a term in the county jail

\begin{tabular}{|c|c|c|c|c|c|c|c|c|c|c|c|c|c|c|c|c|c|c|c|c|c|}
\hline \multirow[b]{2}{*}{ Variables } & \multicolumn{7}{|c|}{ Regressed alone } & \multicolumn{7}{|c|}{ Regressed in full } & \multicolumn{7}{|c|}{ Best fit regression } \\
\hline & $x^{2}$ & $p$ & Pseudo $\mathrm{R}^{2}$ & $\beta$ & $\%$ Chg & $z$ & $p$ & $x^{2}$ & $p$ & Pseudo $\mathrm{R}^{2}$ & $\beta$ & $\%$ Chg & $\mathbf{z}$ & $p$ & $x^{2}$ & $p$ & Pseudo $\mathrm{R}^{2}$ & $\beta$ & $\%$ Chg & $z$ & $p$ \\
\hline Model & & & & & & & & 209 & .000 & .442 & & & & & 204 & .000 & .427 & & & & \\
\hline Susp. Was Arrested & 6.63 & .010 & .014 & .566 & 76 & 2.57 & .010 & & & & -.385 & -32 & .93 & .352 & & & & & & & \\
\hline Sum, Witnesses & 3.55 & .060 & .007 & .390 & 48 & 1.89 & .059 & & & & -.862 & -58 & .94 & .348 & & & & & & & \\
\hline PD Inv. Time < 240 hrs. & 15.7 & .000 & .033 & .873 & 139 & 3.92 & .000 & & & & .806 & 124 & 2.19 & .028 & & & & .736 & 109 & 2.32 & .020 \\
\hline Word Count - Police Report & 3.58 & .059 & .008 & .0005 & .048 & 1.89 & .059 & & & & .0003 & .03 & .68 & .499 & & & & & & & \\
\hline Charge Count - Police & 21.5 & .000 & .045 & .620 & 86 & 4.41 & .000 & & & & .301 & 35 & 1.44 & .150 & & & & & & & \\
\hline Charge Count - Filed & 48.0 & .000 & .101 & .637 & 89 & 6.37 & .000 & & & & -.191 & -17 & .99 & .323 & & & & & & & \\
\hline Charge Count - Conv. & 130.0 & .000 & .272 & 2.27 & 965 & 9.24 & .000 & & & & -.278 & -24 & .43 & .671 & & & & & & & \\
\hline Conv. $\geq 1$ Misd. DV & 145 & .000 & .303 & 3.11 & 2100 & 10.5 & .000 & & & & 4.34 & 667 & 5.65 & .000 & & & & 3.90 & 4800 & 10.7 & .000 \\
\hline Conv. $\geq 1$ Fel. DV & 5.51 & .019 & .012 & .842 & 132 & 2.35 & .019 & & & & 2.25 & 853 & 2.89 & .004 & & & & 2.07 & 694 & 4.64 & .000 \\
\hline Conv. $\geq 1$ Non-DV Crime & 5.68 & .017 & .012 & .775 & 117 & 2.39 & .017 & & & & 2.07 & 691 & 2.51 & .012 & & & & 1.60 & 396 & 3.66 & .000 \\
\hline 5th Amend. Invoked & 6.38 & .012 & .013 & 1.10 & 200 & 2.49 & .013 & & & & .509 & 66 & .65 & .515 & & & & & & & \\
\hline Susp. Admits Guilt & 3.21 & .073 & .007 & .573 & 77 & 1.80 & .071 & & & & .180 & 20 & .25 & .803 & & & & & & & \\
\hline Susp. Denies Guilt & 6.74 & .009 & .014 & -.611 & -46 & 2.60 & .009 & & & & -.217 & -20 & .38 & .705 & & & & & & & \\
\hline Susp. Sex: Male & 8.76 & .003 & .018 & 1.05 & 186 & 2.73 & .006 & & & & .748 & 111 & 1.25 & .210 & & & & & & & \\
\hline Susp. Race: White & 3.74 & .053 & .008 & -.586 & -44 & 1.87 & .061 & & & & .069 & 7.16 & .14 & .890 & & & & & & & \\
\hline Susp. Age & 9.14 & .003 & .019 & -.033 & -3.26 & 2.92 & .004 & & & & -.031 & -3.03 & 1.08 & .279 & & & & -.036 & -3.51 & 2.17 & .030 \\
\hline Vict. Age & 6.44 & .011 & .014 & -.029 & -2.87 & 2.48 & .013 & & & & -.00. & -.26 & .09 & .928 & & & & & & & \\
\hline No Witnesses & 4.02 & .015 & .008 & -.468 & -37 & 2.01 & .044 & & & & -1.02 & -63.9 & .98 & .327 & & & & & & & \\
\hline$\geq 1$ Juv. Victims & 4.55 & .033 & .010 & .891 & 144 & 2.13 & .033 & & & & .334 & 39.7 & .50 & .615 & & & & & & & \\
\hline
\end{tabular}


Table 5 By antecedent, percentage change and odds of a Harvey waiver being granted

\begin{tabular}{|c|c|c|c|c|c|c|c|c|c|c|c|c|c|c|c|c|c|c|c|c|c|}
\hline \multirow[b]{2}{*}{ Variables } & \multicolumn{7}{|c|}{ Regressed alone } & \multicolumn{7}{|c|}{ Regressed in full } & \multicolumn{7}{|c|}{ Best fit regression } \\
\hline & $x^{2}$ & $p$ & Pseudo $\mathrm{R}^{2}$ & $\beta$ & $\%$ Chg & $z$ & $p$ & $x^{2}$ & $p$ & Pseudo $\mathrm{R}^{2}$ & $\beta$ & $\%$ Chg & $z$ & $p$ & $x^{2}$ & $p$ & Pseudo $\mathrm{R}^{2}$ & $\beta$ & $\%$ Chg & $z$ & $p$ \\
\hline Model & & & & & & & & 9.57 & .023 & .124 & & & & & 9.53 & .009 & .124 & & & & \\
\hline Charge Count - Filed & 4.81 & .028 & .062 & .522 & 69 & 2.31 & .021 & & & & .414 & 51 & 1.26 & .207 & & & & .451 & 57 & 1.71 & .087 \\
\hline Charge Count - Conv. & 4.58 & .032 & .060 & .944 & 157 & 2.27 & .023 & & & & .150 & 16 & .20 & .845 & & & & & & & \\
\hline Conv. $\geq 1$ Misd. DV & 6.94 & .009 & .090 & 1.98 & 623 & 2.40 & .016 & & & & 1.60 & 395 & 1.79 & .074 & & & & 1.67 & 430 & 2.00 & .046 \\
\hline
\end{tabular}


Table 6 By antecedent, percentage change and odds of probation

\begin{tabular}{|c|c|c|c|c|c|c|c|c|c|c|c|c|c|c|c|c|c|c|c|c|c|}
\hline \multirow[b]{2}{*}{ Variables } & \multicolumn{7}{|c|}{ Regressed alone } & \multicolumn{7}{|c|}{ Regressed in full } & \multicolumn{7}{|c|}{ Best fit regression } \\
\hline & $x^{2}$ & $p$ & Pseudo $\mathrm{R}^{2}$ & $\beta$ & $\%$ Chg & $z$ & $p$ & $x^{2}$ & $p$ & Pseudo $\mathrm{R}^{2}$ & $\beta$ & $\%$ Chg & $z$ & $p$ & $x^{2}$ & $p$ & Pseudo $\mathrm{R}^{2}$ & $\beta$ & $\%$ Chg & $\mathbf{z}$ & $p$ \\
\hline Model & & & & & & & & 229 & .000 & .475 & & & & & 220 & .000 & .450 & & & & \\
\hline Susp. Was Arrested & 7.58 & .006 & .016 & .599 & 82 & 2.74 & .006 & & & & -.033 & -3.20 & .08 & .936 & & & & & & & \\
\hline PD Inv. Time < 240 hrs. & 16.9 & .000 & .035 & .898 & 146 & 4.07 & .000 & & & & .864 & 137 & 2.34 & .019 & & & & .769 & 116 & 2.39 & .017 \\
\hline Word Count - Police Report & 3.46 & .063 & .001 & .0005 & .05 & 1.85 & .064 & & & & -.000 & -.004 & .09 & .927 & & & & & & & \\
\hline Charge Count - Police & 24.2 & .000 & .050 & .662 & 94 & 4.62 & .000 & & & & .107 & 11 & .51 & .614 & & & & & & & \\
\hline Charge Count - Filed & 74.8 & .000 & .154 & .841 & 131 & 7.52 & .000 & & & & .042 & 4.25 & .22 & .826 & & & & & & & \\
\hline Charge Count - Conv. & 179 & .000 & .367 & 2.91 & 1600 & 10.1 & .000 & & & & .023 & 2.20 & .03 & .975 & & & & & & & \\
\hline Conv. $\geq 1$ Misd. DV & 131 & .000 & .269 & 2.92 & 1700 & 10.0 & .000 & & & & 4.00 & 446 & 4.96 & .000 & & & & 4.07 & 5600 & 10.7 & .000 \\
\hline Conv. $\geq 1$ Fel. DV & 15.2 & .000 & .031 & 1.42 & 315 & 3.73 & .000 & & & & 2.59 & 1200 & 3.09 & .002 & & & & 2.80 & 1400 & 5.80 & .000 \\
\hline Conv. $\geq 1$ Non-DV Crime & 16.4 & .000 & .034 & 1.33 & 278 & 3.92 & .000 & & & & 2.31 & 900 & 2.59 & .010 & & & & 2.57 & 1100 & 5.52 & .000 \\
\hline 5th Amend. Invoked & 5.40 & .020 & .011 & 1.01 & 174 & 2.29 & .022 & & & & .277 & 33 & .45 & .653 & & & & & & & \\
\hline Susp. Sex: Male & 10.5 & .001 & .022 & 1.15 & 214 & 2.97 & .003 & & & & .808 & 124 & 1.37 & .171 & & & & & & & \\
\hline Susp. Race: White & 3.87 & .049 & .008 & -.587 & -44 & 1.91 & .056 & & & & .201 & 22 & .40 & .690 & & & & & & & \\
\hline Susp. Age & 7.67 & .006 & .016 & -.030 & -2.93 & 2.69 & .007 & & & & -.046 & -4.53 & 1.57 & .117 & & & & & & & \\
\hline Vict. Age & 4.66 & .031 & .010 & -.024 & -2.40 & 2.12 & .034 & & & & .022 & 2.24 & .74 & .461 & & & & & & & \\
\hline
\end{tabular}


Table 7 By antecedent, percentage change and odds of being ordered to pay restitution to the victim(s)

\begin{tabular}{|c|c|c|c|c|c|c|c|c|c|c|c|c|c|c|c|c|c|c|c|c|c|}
\hline \multirow[b]{2}{*}{ Variables } & \multicolumn{7}{|c|}{ Regressed alone } & \multicolumn{7}{|c|}{ Regressed in full } & \multicolumn{7}{|c|}{ Best fit regression } \\
\hline & $x^{2}$ & $p$ & Pseudo $\mathrm{R}^{2}$ & $\beta$ & $\%$ Chg & $\mathbf{z}$ & $p$ & $x^{2}$ & $p$ & Pseudo $\mathrm{R}^{2}$ & $\beta$ & $\%$ Chg & $\mathbf{z}$ & $p$ & $x^{2}$ & $p$ & Pseudo $\mathrm{R}^{2}$ & $\beta$ & $\%$ Chg & $z$ & $p$ \\
\hline Model & & & & & & & & 69.2 & .000 & .250 & & & & & 63.1 & .000 & .228 & & & & \\
\hline Charge Count - Filed & 14.1 & .000 & .051 & .430 & 54 & 3.82 & .000 & & & & -.001 & -.150 & .01 & .994 & & & & & & & \\
\hline Charge Count - Conv. & 33.1 & .000 & .120 & 1.28 & 261 & 5.41 & .000 & & & & .055 & 5.70 & .12 & .904 & & & & & & & \\
\hline Conv. $\geq 1$ Misd. DV & 24.3 & .000 & .088 & 1.60 & 395 & 4.83 & .000 & & & & 2.83 & 1600 & 4.21 & .000 & & & & 2.95 & 1800 & 5.37 & .000 \\
\hline Conv. $\geq 1$ Fel. DV & 15.8 & .000 & .057 & 1.67 & 434 & 4.24 & .000 & & & & 3.29 & 2500 & 4.18 & .000 & & & & 3.46 & 3000 & 5.64 & .000 \\
\hline Susp. Sex: Male & 4.91 & .027 & .018 & 1.36 & 288 & 1.83 & .067 & & & & .805 & 124 & 1.01 & .310 & & & & & & & \\
\hline Vict. Race: White & 4.65 & .031 & .017 & -.855 & -58 & 2.00 & .046 & & & & -.722 & -51 & 1.55 & .121 & & & & & & & \\
\hline Vict. Age & 3.56 & .059 & .013 & -.032 & -3.19 & 1.81 & .070 & & & & -.028 & -2.78 & 1.34 & .180 & & & & & & & \\
\hline
\end{tabular}


Table 8 By antecedent, percentage change and odds of being ordered to obey all laws

\begin{tabular}{|c|c|c|c|c|c|c|c|c|c|c|c|c|c|c|c|c|c|c|c|c|c|}
\hline \multirow[b]{2}{*}{ Variables } & \multicolumn{7}{|c|}{ Regressed alone } & \multicolumn{7}{|c|}{ Regressed in full } & \multicolumn{7}{|c|}{ Best fit regression } \\
\hline & $x^{2}$ & $p$ & Pseudo $\mathrm{R}^{2}$ & $\beta$ & $\%$ Chg & $z$ & $p$ & $x^{2}$ & $p$ & Pseudo $\mathrm{R}^{2}$ & $\beta$ & $\%$ Chg & $\mathbf{z}$ & $p$ & $x^{2}$ & $p$ & Pseudo $\mathrm{R}^{2}$ & $\beta$ & $\%$ Chg & $z$ & $p$ \\
\hline Model & & & & & & & & 89.0 & .000 & .267 & & & & & 86.8 & .000 & .261 & & & & \\
\hline Charge Count - Police & 3.21 & .073 & .010 & .278 & 32 & 1.85 & .065 & & & & -.254 & -22 & 1.27 & .205 & & & & & & & \\
\hline Charge Count - Filed & 27.6 & .000 & .083 & .546 & 73 & 5.16 & .000 & & & & .037 & 3.78 & .20 & .845 & & & & & & & \\
\hline Charge Count - Conv. & 64.3 & .000 & .193 & 1.71 & 454 & 7.04 & .000 & & & & 1.12 & 207 & 1.75 & .081 & & & & 1.06 & 189 & 3.14 & .002 \\
\hline Conv. $\geq 1$ Misd. DV & 38.1 & .000 & .114 & 1.79 & 497 & 5.99 & .000 & & & & 1.70 & 450 & 2.35 & .019 & & & & 1.70 & 448 & 3.49 & .000 \\
\hline Conv. $\geq 1$ Fel. DV & 11.9 & .001 & .036 & 1.37 & 293 & 3.61 & .000 & & & & 1.58 & 385 & 2.08 & .037 & & & & 1.58 & 384 & 2.56 & .011 \\
\hline Conv. $\geq 1$ Non-DV Crime & 5.00 & .026 & .015 & .849 & 134 & 2.32 & .000 & & & & .027 & 2.75 & .03 & .972 & & & & & & & \\
\hline 5th Amend. Invoked & 6.92 & .009 & .021 & 1.26 & 252 & 2.78 & .005 & & & & .897 & 145 & 1.71 & .088 & & & & .897 & 145 & 1.77 & .077 \\
\hline Susp. Race: White & 3.34 & .068 & .010 & -.767 & -54 & 1.69 & .091 & & & & -.389 & -32 & .72 & .470 & & & & & & & \\
\hline Susp. Age & 4.78 & .029 & .014 & -.031 & -3.10 & 2.09 & .037 & & & & -.035 & -3.40 & 1.17 & .240 & & & & -.032 & -3.12 & 1.75 & .079 \\
\hline Vict. Age & 3.87 & .050 & .012 & -.030 & -2.91 & 1.90 & .057 & & & & .004 & -90 & .140 & .892 & & & & & & & \\
\hline
\end{tabular}


Table 9 By antecedent, percentage change and odds of being ordered not to commit the same or similar offenses again

\begin{tabular}{|c|c|c|c|c|c|c|c|c|c|c|c|c|c|c|c|c|c|c|c|c|c|}
\hline \multirow[b]{2}{*}{ Variables } & \multicolumn{7}{|c|}{ Regressed alone } & \multicolumn{7}{|c|}{ Regressed in full } & \multicolumn{7}{|c|}{ Best fit regression } \\
\hline & $x^{2}$ & $p$ & Pseudo $\mathrm{R}^{2}$ & $\beta$ & $\%$ Chg & $z$ & $p$ & $x^{2}$ & $p$ & Pseudo $\mathrm{R}^{2}$ & $\beta$ & $\%$ Chg & $z$ & $p$ & $x^{2}$ & $p$ & Pseudo $\mathrm{R}^{2}$ & $\beta$ & $\%$ Chg & $z$ & $p$ \\
\hline Model & & & & & & & & 46.6 & .000 & .206 & & & & & 32.8 & .000 & .145 & & & & \\
\hline Charge Count - Filed & 21.3 & .000 & .094 & .586 & 80 & 4.62 & .000 & & & & .102 & 11 & .52 & .603 & & & & & & & \\
\hline Charge Count - Conv. & 38.1 & .000 & .168 & 1.57 & 382 & 5.60 & .000 & & & & .849 & 134 & 1.27 & .204 & & & & & & & \\
\hline Conv. $\geq 1$ Misd. DV & 6.36 & .012 & .028 & .929 & 153 & 2.55 & .011 & & & & .853 & 135 & 1.08 & .278 & & & & 1.67 & 432 & 3.57 & .000 \\
\hline Conv. $\geq 1$ Fel. DV & 12.8 & .001 & .054 & 1.63 & 412 & 3.80 & .000 & & & & 1.43 & 319 & 1.75 & .080 & & & & 2.71 & 1400 & 4.89 & .000 \\
\hline Conv. $\geq 1$ Non-DV Crime & 11.1 & .001 & .050 & 1.47 & 333 & 3.58 & .000 & & & & .490 & 63 & .61 & .542 & & & & & & & \\
\hline 5th Amend. Invoked & 3.48 & .062 & .015 & 1.10 & 201 & 2.03 & .042 & & & & .650 & 92 & 1.08 & .278 & & & & & & & \\
\hline Vict Race: Black & 3.69 & .055 & .016 & -.948 & -61 & 1.73 & .083 & & & & -1.09 & -98 & 1.81 & .071 & & & & -1.21 & -70 & 2.09 & .037 \\
\hline
\end{tabular}


Table 10 By antecedent, percentage change and odds of being fined

\begin{tabular}{|c|c|c|c|c|c|c|c|c|c|c|c|c|c|c|c|c|c|c|c|c|c|}
\hline \multirow[b]{2}{*}{ Variables } & \multicolumn{7}{|c|}{ Regressed alone } & \multicolumn{7}{|c|}{ Regressed in full } & \multicolumn{7}{|c|}{ Best fit regression } \\
\hline & $x^{2}$ & $p$ & Pseudo $\mathrm{R}^{2}$ & $\beta$ & $\%$ Chg & $z$ & $p$ & $x^{2}$ & $p$ & Pseudo $\mathrm{R}^{2}$ & $\beta$ & $\%$ Chg & $z$ & $p$ & $x^{2}$ & $p$ & Pseudo $\mathrm{R}^{2}$ & $\beta$ & $\%$ Chg & $z$ & $p$ \\
\hline Model & & & & & & & & 110 & .000 & .273 & & & & & 108 & .000 & .269 & & & & \\
\hline PD Inv. Time $<240$ hrs. & 12.8 & .003 & .032 & .888 & 143 & 3.53 & .000 & & & & .517 & 68 & 1.72 & .085 & & & & .537 & 71 & 1.82 & .068 \\
\hline Charge Count - Filed & 24.6 & .000 & .061 & .469 & 60 & 4.86 & .000 & & & & -.113 & -11 & .69 & .487 & & & & & & & \\
\hline Charge Count - Conv. & 75.0 & .000 & .187 & 1.69 & 443 & 7.56 & .000 & & & & .730 & 107 & 1.76 & .079 & & & & .565 & 76 & 1.72 & .085 \\
\hline Conv. $\geq 1$ Misd. DV & 47.5 & .000 & .118 & 1.78 & 494 & 6.73 & .000 & & & & 2.00 & 640 & 4.29 & .000 & & & & 2.08 & 700 & 4.57 & .000 \\
\hline Conv. $\geq 1$ Fel. DV & 23.6 & .000 & .059 & 1.80 & 502 & 4.83 & .000 & & & & 2.35 & 945 & 3.94 & .000 & & & & 2.36 & 963 & 4.05 & .000 \\
\hline 5th Amend. Invoked & 2.87 & .090 & .007 & .781 & 118 & 1.75 & .080 & & & & .237 & 27 & .35 & .723 & & & & & & & \\
\hline Susp. Admits Guilt & 3.27 & .071 & .008 & .626 & 87 & 1.86 & .064 & & & & .429 & 54 & .72 & .474 & & & & & & & \\
\hline Susp. Denies Guilt & 5.74 & .017 & .014 & -.623 & -46 & 2.42 & .015 & & & & .060 & 6.22 & .12 & .903 & & & & & & & \\
\hline
\end{tabular}


Table 11 By antecedent, percentage change and odds of being ordered to attend a domestic violence re-education course

\begin{tabular}{|c|c|c|c|c|c|c|c|c|c|c|c|c|c|c|c|c|c|c|c|c|c|}
\hline \multirow[b]{2}{*}{ Variables } & \multicolumn{7}{|c|}{ Regressed alone } & \multicolumn{7}{|c|}{ Regressed in full } & \multicolumn{7}{|c|}{ Best fit regression } \\
\hline & $x^{2}$ & $p$ & Pseudo $\mathrm{R}^{2}$ & $\beta$ & $\%$ Chg & $z$ & $p$ & $x^{2}$ & $p$ & Pseudo $\mathrm{R}^{2}$ & $\beta$ & $\%$ Chg & $z$ & $p$ & $x^{2}$ & $p$ & Pseudo $\mathrm{R}^{2}$ & $\beta$ & $\%$ Chg & $z$ & $p$ \\
\hline Model & & & & & & & & 117 & .000 & 292 & & & & & 113 & .000 & .284 & & & & \\
\hline Photos Req. or Obtained & 8.32 & .004 & .021 & .795 & 121 & 2.77 & .006 & & & & .566 & 76 & 1.63 & .103 & & & & .642 & 90 & 1.90 & .057 \\
\hline Susp. Was Arrested & 4.34 & .037 & .011 & .516 & 67 & 2.08 & .038 & & & & .038 & 3.83 & .12 & .903 & & & & & & & \\
\hline Charge Count - Police & 30.9 & .000 & .078 & .531 & 70 & 5.38 & .000 & & & & .002 & .248 & .02 & .988 & & & & & & & \\
\hline Charge Count - Conv. & 70.7 & .000 & .177 & 1.63 & 413 & 7.41 & .000 & & & & .344 & 41 & .85 & .395 & & & & & & & \\
\hline Conv. $\geq 1$ Misd. DV & 64.6 & .000 & .162 & 2.11 & 723 & 7.70 & .000 & & & & 2.61 & 1200 & 5.42 & .000 & & & & 2.99 & 1800 & 8.20 & .000 \\
\hline Conv. $\geq 1$ Fel. DV & 14.4 & .000 & .036 & 1.41 & 310 & 3.87 & .000 & & & & 2.37 & 970 & 3.88 & .000 & & & & 2.86 & 1600 & 6.18 & .000 \\
\hline 5th Amend. Invoked & 6.97 & .008 & .018 & 1.19 & 228 & 2.71 & .007 & & & & .538 & 71 & 1.00 & .317 & & & & & & & \\
\hline Susp. Sex: Male & 3.21 & .073 & .008 & .717 & 105 & 1.68 & .094 & & & & .086 & .248 & .16 & .870 & & & & & & & \\
\hline Vict. Age & 3.03 & .082 & .008 & -.023 & -2.21 & 1.70 & .089 & & & & -.017 & -95 & 1.03 & .305 & & & & & & & \\
\hline
\end{tabular}


Table 12 By antecedent, percentage change and odds of having gun ownership or possession prohibited

\begin{tabular}{|c|c|c|c|c|c|c|c|c|c|c|c|c|c|c|c|c|c|c|c|c|c|}
\hline \multirow[b]{2}{*}{ Variables } & \multicolumn{7}{|c|}{ Regressed alone } & \multicolumn{7}{|c|}{ Regressed in full } & \multicolumn{7}{|c|}{ Best fit regression } \\
\hline & $x^{2}$ & $p$ & Pseudo $\mathrm{R}^{2}$ & $\beta$ & $\%$ Chg & $z$ & $p$ & $x^{2}$ & $p$ & Pseudo $R^{2}$ & $\beta$ & $\%$ Chg & $z$ & $p$ & $x^{2}$ & $p$ & Pseudo $\mathrm{R}^{2}$ & $\beta$ & $\%$ Chg & $z$ & $p$ \\
\hline Model & & & & & & & & 93.1 & .000 & .280 & & & & & 90.3 & .000 & .271 & & & & \\
\hline Charge Count - Filed & 16.9 & .000 & .051 & .426 & 53 & 4.13 & .000 & & & & -.176 & -16 & .96 & .337 & & & & & & & \\
\hline Charge Count - Conv. & 51.5 & .000 & .155 & 1.49 & 344 & 6.52 & .000 & & & & .674 & 96 & 1.51 & .130 & & & & & & & \\
\hline Conv. $\geq 1$ Misd. DV & 45.6 & .000 & .137 & 1.97 & 615 & 6.47 & .000 & & & & 2.72 & 52 & 4.65 & .000 & & & & 3.21 & 2300 & 6.77 & .000 \\
\hline Conv. $\geq 1$ Fel. DV & 11.9 & .001 & .036 & 1.37 & 293 & 3.61 & .000 & & & & 2.70 & 1300 & 3.79 & .000 & & & & 3.30 & 2600 & 5.94 & .000 \\
\hline 5th Amend. Invoked & 4.61 & .032 & .014 & 1.05 & 185 & 2.27 & .023 & & & & .511 & 67 & .93 & .353 & & & & & & & \\
\hline Susp. Sex: Male & 3.62 & .057 & .011 & .808 & 124 & 1.99 & .046 & & & & 1.45 & -98 & 2.70 & .007 & & & & 1.38 & 296 & 2.59 & .010 \\
\hline
\end{tabular}


Table 13 By antecedent, percentage change and odds of being ordered to stay away from the victim(s)

\begin{tabular}{|c|c|c|c|c|c|c|c|c|c|c|c|c|c|c|c|c|c|c|c|c|c|}
\hline \multirow[b]{2}{*}{ Variables } & \multicolumn{7}{|c|}{ Regressed alone } & \multicolumn{7}{|c|}{ Regressed in full } & \multicolumn{7}{|c|}{ Best fit regression } \\
\hline & $x^{2}$ & $p$ & Pseudo $\mathrm{R}^{2}$ & $\beta$ & $\%$ Chg & $\mathbf{z}$ & $p$ & $x^{2}$ & $p$ & Pseudo $\mathrm{R}^{2}$ & $\beta$ & $\%$ Chg & $\mathbf{z}$ & $p$ & $x^{2}$ & $p$ & Pseudo $\mathrm{R}^{2}$ & $\beta$ & $\%$ Chg & $\mathbf{z}$ & $p$ \\
\hline Model & & & & & & & & 121 & .000 & .326 & & & & & 115 & .000 & .311 & & & & \\
\hline EPO Obtained & 4.10 & .043 & .011 & .530 & 70 & 2.03 & .042 & & & & .168 & 18.3 & .51 & .613 & & & & & & & \\
\hline Susp. Was Arrested & 11.8 & .001 & .032 & .901 & 146 & 3.39 & .001 & & & & .352 & 42.1 & .96 & .336 & & & & & & & \\
\hline Sum, Witnesses & 5.17 & .023 & .014 & .536 & 71 & 2.31 & .021 & & & & -.101 & -10 & .11 & .912 & & & & & & & \\
\hline PD Inv. Time < 240 hrs. & 24.2 & .000 & .065 & 1.31 & 272 & 4.72 & .000 & & & & 1.23 & 243 & 3.35 & .001 & & & & 1.40 & 304 & 4.26 & .000 \\
\hline Charge Count - Police & 18.4 & .000 & .050 & .614 & 84 & 4.25 & .000 & & & & .110 & 12 & .54 & .589 & & & & & & & \\
\hline Charge Count - Filed & 40.8 & .000 & .110 & .638 & 89 & 6.07 & .000 & & & & .290 & 34 & 1.60 & .110 & & & & .378 & 45.9 & 2.68 & .007 \\
\hline Charge Count - Conv. & 61.3 & .000 & .165 & 1.56 & 374 & 7.00 & .000 & & & & .171 & 19 & .39 & .696 & & & & & & & \\
\hline Conv. $\geq 1$ Misd. DV & 67.7 & .000 & .182 & 2.27 & 868 & 7.75 & .000 & & & & 2.17 & 772 & 4.55 & .000 & & & & 2.34 & 940 & 6.39 & .000 \\
\hline Conv. $\geq 1$ Non-DV Crime & 6.84 & .009 & .018 & .935 & 155 & 2.71 & .007 & & & & .902 & 146 & 1.38 & .166 & & & & 1.08 & 195 & 2.13 & .033 \\
\hline 5th Amend. Invoked & 2.72 & .099 & .007 & .787 & 120 & 1.72 & .086 & & & & -.198 & -18 & .33 & .743 & & & & & & & \\
\hline Susp. Sex: Male & 6.64 & .010 & .018 & 1.20 & 233 & 2.24 & .025 & & & & .904 & 147 & 1.40 & .163 & & & & 1.04 & 183 & 1.66 & .097 \\
\hline Susp. Age & 4.88 & .027 & .013 & -.029 & -2.88 & 2.12 & .034 & & & & -.027 & -2.64 & 1.43 & .152 & & & & & & & \\
\hline No Witnesses & 4.66 & .031 & .013 & -.585 & -44 & 2.18 & .029 & & & & -.321 & -28 & .31 & .753 & & & & & & & \\
\hline$\geq 1$ Juv. Victim & 5.37 & .021 & .015 & 1.01 & 183 & 2.41 & .016 & & & & .647 & 91.0 & 1.00 & .316 & & & & & & & \\
\hline
\end{tabular}


Table 14 By antecedent, percentage change and odds of random or scheduled drug testing being ordered

\begin{tabular}{|c|c|c|c|c|c|c|c|c|c|c|c|c|c|c|c|c|c|c|c|c|c|}
\hline \multirow[b]{2}{*}{ Variables } & \multicolumn{7}{|c|}{ Regressed alone } & \multicolumn{7}{|c|}{ Regressed in full } & \multicolumn{7}{|c|}{ Best fit regression } \\
\hline & $x^{2}$ & $p$ & Pseudo $\mathrm{R}^{2}$ & $\beta$ & $\%$ Chg & $z$ & $p$ & $x^{2}$ & $p$ & Pseudo $\mathrm{R}^{2}$ & $\beta$ & $\%$ Chg & $z$ & $p$ & $x^{2}$ & $p$ & Pseudo $\mathrm{R}^{2}$ & $\beta$ & $\%$ Chg & $\mathbf{z}$ & $p$ \\
\hline Model & & & & & & & & 5.15 & .076 & .148 & & & & & 4.98 & .026 & .143 & & & & \\
\hline Charge Count - Conv. & 2.95 & .086 & .085 & 1.14 & 213 & 1.90 & .057 & & & & .374 & 45 & .43 & .670 & & & & & & & \\
\hline Conv. $\geq 1$ Non-DV Crime & 4.98 & .026 & .143 & 2.73 & 1400 & 2.21 & .027 & & & & 2.30 & 894 & 1.43 & .152 & & & & 2.73 & 1400 & 2.21 & .027 \\
\hline
\end{tabular}


Table 15 By antecedent, percentage change and odds of a search waiver being imposed

\begin{tabular}{|c|c|c|c|c|c|c|c|c|c|c|c|c|c|c|c|c|c|c|c|c|c|}
\hline \multirow[b]{2}{*}{ Variables } & \multicolumn{7}{|c|}{ Regressed alone } & \multicolumn{7}{|c|}{ Regressed in full } & \multicolumn{7}{|c|}{ Best fit regression } \\
\hline & $x^{2}$ & $p$ & Pseudo $\mathrm{R}^{2}$ & $\beta$ & $\%$ Chg & $\mathbf{z}$ & $p$ & $x^{2}$ & $p$ & Pseudo $\mathrm{R}^{2}$ & $\beta$ & $\%$ Chg & $z$ & $p$ & $x^{2}$ & $p$ & Pseudo $\mathrm{R}^{2}$ & $\beta$ & $\%$ Chg & $z$ & $p$ \\
\hline Model & & & & & & & & 132 & .000 & .381 & & & & & 123 & .000 & .355 & & & & \\
\hline Susp. Was Arrested & 3.81 & .051 & .011 & .533 & 70 & 1.95 & .052 & & & & -.163 & -15 & .40 & .688 & & & & & & & \\
\hline Sum, Witnesses & 4.41 & .036 & .013 & -.610 & -46 & 1.98 & .048 & & & & -1.49 & -77 & 1.22 & .224 & & & & -1.35 & -74 & 3.72 & .000 \\
\hline PD Inv. Time $<240$ hrs. & 7.14 & .008 & .021 & .732 & 108 & 2.65 & .008 & & & & .348 & 42 & .86 & .392 & & & & & & & \\
\hline Charge Count - Filed & 14.8 & .000 & .043 & .392 & 48 & 3.87 & .000 & & & & -.250 & -222 & 1.25 & .210 & & & & & & & \\
\hline Charge Count - Conv. & 57.4 & .000 & .166 & 1.56 & 375 & 6.80 & .000 & & & & .902 & 146 & 1.84 & .066 & & & & & & & \\
\hline Conv. $\geq 1$ Misd. DV & 54.6 & .000 & .158 & 2.12 & 732 & 7.01 & .000 & & & & 3.15 & 2200 & 4.90 & .000 & & & & 3.81 & 4300 & 7.24 & .000 \\
\hline Conv. $\geq 1$ Fel. DV & 13.2 & .000 & .038 & 1.42 & 312 & 3.78 & .000 & & & & 3.10 & 2100 & 3.95 & .000 & & & & 4.01 & 5400 & 6.52 & .000 \\
\hline 5th Amend. Invoked & 3.95 & .047 & .011 & .963 & 162 & 2.09 & .037 & & & & .400 & 49 & .51 & .612 & & & & & & & \\
\hline Susp. Admits Guilt & 3.36 & .067 & .010 & .685 & 98 & 1.90 & .057 & & & & -.055 & -5.35 & .08 & .938 & & & & & & & \\
\hline Susp. Denies Guilt & 5.86 & .016 & .017 & -.689 & -50 & 2.45 & .014 & & & & -.453 & -37 & .75 & .456 & & & & & & & \\
\hline Vict. Race: Asian & 4.03 & .045 & .012 & .864 & 137 & 2.10 & .036 & & & & 1.67 & 433 & 2.66 & .008 & & & & 1.79 & 6.00 & 3.00 & .003 \\
\hline Vict. Race: White & 4.03 & .045 & .012 & -.657 & -48 & 1.91 & .056 & & & & -.383 & -32 & .88 & .378 & & & & & & & \\
\hline Vict. Age & 3.64 & .056 & .011 & -.028 & -2.74 & 1.85 & .064 & & & & -.025 & -2.49 & 1.27 & .203 & & & & & & & \\
\hline No Witnesses & 3.72 & .054 & .011 & .604 & 83 & 1.86 & .063 & & & & .008 & -93 & .01 & .995 & & & & & & & \\
\hline
\end{tabular}




\section{Table 16 By antecedent, percentage change and odds of being sentenced to a term in state prison}

\begin{tabular}{|c|c|c|c|c|c|c|c|c|c|c|c|c|c|c|c|c|c|c|c|c|c|}
\hline \multirow[b]{2}{*}{ Variables } & \multicolumn{7}{|c|}{ Regressed alone } & \multicolumn{7}{|c|}{ Regressed in full } & \multicolumn{7}{|c|}{ Best fit regression } \\
\hline & $x^{2}$ & $p$ & Pseudo $\mathrm{R}^{2}$ & $\beta$ & $\%$ Chg & z & $p$ & $x^{2}$ & $p$ & Pseudo $\mathrm{R}^{2}$ & $\beta$ & $\%$ Chg & $\mathbf{z}$ & $p$ & $x^{2}$ & $p$ & Pseudo $\mathrm{R}^{2}$ & $\beta$ & $\%$ Chg & $\mathbf{z}$ & $p$ \\
\hline Model & & & & & & & & 17.85 & .003 & .232 & & & & & 14.09 & .000 & .183 & & & & \\
\hline Charge Count - Filed & 2.93 & .087 & .038 & .418 & 52 & 1.81 & .071 & & & & .079 & 8.25 & .21 & .831 & & & & & & & \\
\hline Charge Count - Conv. & 4.58 & .032 & .060 & .944 & 157 & 2.27 & .023 & & & & -.679 & -49 & .60 & .545 & & & & & & & \\
\hline Conv. $\geq 1$ Fel. DV & 14.1 & .000 & .183 & 2.90 & 1700 & 3.85 & .000 & & & & 3.12 & 2100 & 2.80 & .005 & & & & 2.90 & 1700 & 3.85 & .000 \\
\hline Conv. $\geq 1$ Non-DV Crime & 3.52 & .061 & .046 & 1.53 & 364 & 2.05 & .040 & & & & 1.60 & 397 & 1.19 & .233 & & & & & & & \\
\hline$\geq 1$ Juv. Victim & 2.68 & .102 & .035 & 1.58 & 386 & 1.87 & .061 & & & & 1.56 & 377 & 1.71 & .088 & & & & & & & \\
\hline
\end{tabular}


Table 17 By antecedent, percentage change and odds of being ordered not to use drugs or alcohol

\begin{tabular}{|c|c|c|c|c|c|c|c|c|c|c|c|c|c|c|c|c|c|c|c|c|c|}
\hline \multirow[b]{2}{*}{ Variables } & \multicolumn{7}{|c|}{ Regressed alone } & \multicolumn{7}{|c|}{ Regressed in full } & \multicolumn{7}{|c|}{ Best fit regression } \\
\hline & $x^{2}$ & $p$ & Pseudo $\mathrm{R}^{2}$ & $\beta$ & $\%$ Chg & $z$ & $p$ & $x^{2}$ & $p$ & Pseudo $\mathrm{R}^{2}$ & $\beta$ & $\%$ Chg & $z$ & $p$ & $x^{2}$ & $p$ & Pseudo $\mathrm{R}^{2}$ & $\beta$ & $\%$ Chg & z & $p$ \\
\hline Model & & & & & & & & 36.1 & .000 & .204 & & & & & 34.99 & .000 & .198 & & & & \\
\hline Photos Req. or Obtained & 4.13 & .042 & .023 & 1.03 & 180 & 1.85 & .065 & & & & 1.35 & 286 & 2.17 & .030 & & & & 1.28 & 261 & 2.11 & .035 \\
\hline PD Inv. Time $<240$ hrs. & 5.22 & .022 & .030 & .988 & 168 & 2.21 & .027 & & & & .853 & 135 & 1.77 & .077 & & & & .789 & 121 & 1.67 & .095 \\
\hline Charge Count - Filed & 4.04 & .044 & .023 & .306 & 36 & 2.09 & .037 & & & & .013 & 1.29 & .05 & .958 & & & & & & & \\
\hline Charge Count - Conv. & 9.25 & .002 & .052 & .847 & 2.33 & 3.09 & .002 & & & & .175 & 9 & .32 & .752 & & & & & & & \\
\hline Conv. $\geq 1$ Misd. DV & 21.9 & .000 & .124 & 2.08 & 703 & 4.28 & .000 & & & & 1.83 & 533 & 3.12 & .002 & & & & 1.93 & 591 & 3.88 & .000 \\
\hline Susp. Admits Guilt & 7.61 & .006 & .043 & 1.39 & 300 & 2.98 & .003 & & & & 1.85 & 534 & 2.36 & .018 & & & & 1.34 & 284 & 2.60 & .009 \\
\hline Susp. Denies Guilt & 2.95 & .086 & .017 & -.745 & -53 & 1.75 & .081 & & & & .645 & 91 & .92 & .357 & & & & & & & \\
\hline
\end{tabular}


Table 18 By antecedent, percentage change and odds of being ordered not to annoy, threaten, harass, or strike victim(s)

\begin{tabular}{|c|c|c|c|c|c|c|c|c|c|c|c|c|c|c|c|c|c|c|c|c|c|}
\hline \multirow[b]{2}{*}{ Variables } & \multicolumn{7}{|c|}{ Regressed alone } & \multicolumn{7}{|c|}{ Regressed in full } & \multicolumn{7}{|c|}{ Best fit regression } \\
\hline & $x^{2}$ & $p$ & Pseudo $\mathrm{R}^{2}$ & $\beta$ & $\%$ Chg & $\mathbf{z}$ & $p$ & $x^{2}$ & $p$ & Pseudo $\mathrm{R}^{2}$ & $\beta$ & $\%$ Chg & $z$ & $p$ & $x^{2}$ & $p$ & Pseudo $\mathrm{R}^{2}$ & $\beta$ & $\%$ Chg & $z$ & $p$ \\
\hline Model & & & & & & & & 67.9 & .000 & .217 & & & & & 65.0 & .000 & .208 & & & & \\
\hline Photos Req. or Obtained & 4.07 & .044 & .013 & .654 & 92 & 1.94 & .053 & & & & .440 & 55 & 1.15 & .251 & & & & & & & \\
\hline Charge Count - Filed & 11.6 & .001 & .037 & .366 & 44 & 3.46 & .001 & & & & -.160 & -15 & .88 & .381 & & & & & & & \\
\hline Charge Count - Conv. & 34.1 & .000 & 109 & 1.21 & 237 & 5.51 & .000 & & & & .579 & 78 & 1.35 & .177 & & & & & & & \\
\hline Conv. $\geq 1$ Misd. DV & 33.1 & .000 & .106 & 1.73 & 464 & 5.60 & .000 & & & & 2.19 & 793 & 4.09 & .000 & & & & 2.58 & 1200 & 6.20 & .000 \\
\hline Conv. $\geq 1$ Fel. DV & 6.46 & .011 & .021 & 1.07 & 191 & 2.69 & .007 & & & & 1.96 & 609 & 2.87 & .004 & & & & 2.52 & 1100 & 4.87 & .000 \\
\hline Susp. Race: Asian & 6.94 & .008 & .022 & 1.12 & 205 & 2.79 & .005 & & & & 1.65 & 421 & 3.36 & .001 & & & & 1.60 & 141 & 3.28 & .001 \\
\hline
\end{tabular}


crime investigations should exist at every police agency in the United States, and probably across many other countries as well, it should not be too difficult for someone to acquire a national or even international level random sample of sufficient size such that the artifactual findings of the present study will either be replicated or falsified. Either result should prove interesting.

With regard to the natural process, future studies should consider examination of potential relationships between inflections along the slope and explanatory variables such as birth of children, changing of careers, history of domestic violence (both identified and not identified by police), sexual and romantic re-partnering (one shouldn't assume longitudinal data represent a single dyad over time), differences according to the relational and sexual orientation of the dyads (i.e., gay, lesbian, bisexual, transgender, and also heterosexual), and so forth. It would be particularly interesting to collect world-wide data in a manner pioneered by the seminal work of Straus in 2008. In that study Straus collected data from 32 nations, demonstrating rather convincingly, that within and between-sex rates of domestic violence are fairly consistent across the human population. Based upon Straus' results, showing approximately equal rates of domestic violence, for each sex, one might expect to find DV-AVPE patterns similar to those seen in Figure 2 across the nations as well. If that is true, it would further suggest domestic violence is part of the human condition, rather than a sex-linked characteristic.

\section{Making sense of the coefficient}

\section{Review of sentencing components}

An examination of the 16 sub-components of the sentencing coefficient demonstrates individual rates of use ranging from zero to $86 \%$. A variety of antecedents are seen to interact with them as demonstrated in Tables 4, $5,6,7,8,9,10,11,12,13,14,15,16,17,18$. Some of the important interactions are discussed further below.

\section{The importance of multiple charges}

The four strongest antecedents seen in Figure 3 are all related to prosecutors being in possession of police reports that document multiple crimes. This interpretation is felt to be valid because the investigative act of documenting multiple crimes is seen as the genesis of prosecutorial negotiating capital. From police reports that identify multiple crimes flow the potential for prosecutors to file multiple criminal charges. These multiple charges, in turn, permit prosecutors to drop or reduce some charges in exchange for guilty pleas to others.

The sequence starts with the decision of the first responding police officer to thoroughly investigate for concurrent and also past-but-still-chargeable crimes, ${ }^{\mathrm{k}}$ rather than to write a single-crime report. As noted, the choice to be investigatively thorough has been shown to have a significant impact on the criminal justice response to domestic violence crime: The likelihood of prosecution increase about $284 \%$, and the likelihood of criminal conviction increase by about $142 \%$-for each additional crime documented in the FRPO's written report (Nelson, 2013).

In light of the fact that most DV is ongoing, rather than a single incident (Tjaden \& Thoennes, 2000; Felson et al. 2005; Whitaker, Haileyesus et al. 2007; Straus, 2008), and in light of the fact that DV crime in the prior year is chargeable by prosecutors, and in light of the fact that vandalism and child endangerment charges can frequently attend a primary DV crime, and a variety of other charges as well, generally speaking it is difficult to view single-crime DV reports, written by first responding police officers as anything other than markers of insufficient investigative effort.

As Tables 4, 5, 6, 7, 8, 9, 10, 11, 12, 13, 14, 15, 16, 17, 18 and also Figure 3 demonstrate, multiple charges also raise the likelihood that the majority of individual sentencing components will be included in the judge's order. This trend is unidirectional, strong across several measures, and consistent. Five of the six most influential antecedent variables, as shown in Figure 3 are derivatives, in one form or another, of multiple crimes being documented by the first responding police officer. Thus, the choice to thoroughly investigate DV crime in order to document multiple crimes is seen as the essential act that will substantially, significantly, and permanently raise rates of DV prosecution and criminal conviction, and also significantly increase the volume of post-conviction $D V$ criminal sentences. Thus it is predicted that as the number of listed crimes contained in FRPO reports increases a proportional, permanent, and significant increase in these three outcomes will also occur.

Most FRPO written reports alleging DV crime could list additional concurrent and past-but-still-chargeable crimes. As the next section demonstrates, this assertion is strongly supported by a multiplicity of indirect evidence.

Concurrent and prior crime: Creating powerful prosecutorial currency. In any given response to domestic violence crime, the first responding police officer is faced with the choice whether to minimally investigate or to be thorough, knowing the latter option is time consuming. Documenting the primary charge of DV that arises from the current call for service satisfies minimum duty requirements. Once that is done, the choice must be made: Continue on and dig deeper, or cease the investigation, complete the police action, write and submit a report, and move on to the next call for service.

The purpose of this section is to illuminate the many concurrent and also past-but-still-chargeable crimes that 
are left undiscovered by a choice towards professional minimalism. That posit noted, it is important to keep in mind that sometimes even a thorough investigation will only be able to document a single crime. Thus, the section below speaks to probabilities and not to the individual case.

Vandalism: One crime that may often be present is vandalism. The very nature of physical fighting raises the possibility that possessions will be damaged. Things get broken during a fight, either incidentally or intentionally, and in both cases vandalism has occurred and can be listed in the police report. Examples of vandalism can include breaking the victim's phone, perhaps by throwing it against a wall or stomping on it; knocking over/breaking a chair or other furniture; breaking a window either by accident or intention; using keys to scratch a car; spilling motor oil on the carpet as an act of revenge; kicking a hole in a wall or punching a hole in a door; pulling down a mirror or picture; slamming a door so hard that the door frame gets cracked, and so forth. If the domestic crime investigated today resulted in a hole in the wall, officers should look around for other holes, including those that may have been repaired-and then ask about them. The same search can reveal other broken or damaged objects. Interviewing children and witnesses may lead to torn clothing from a prior fight, now in a trash can outside, or a broken vase from a prior DV incident in the trash can outside. All of these represent chargeable vandalism.

Child endangerment: Evidence suggests that domestic violence is committed in or around the presence of children quite often. In California doing so is a misdemeanor ( $\mathrm{CPC} \$ 273 \mathrm{a}(\mathrm{b}))$, and if the children were placed in danger such that great bodily injury could have resulted, the charge is a felony (CPC $\$ 273 a(a))$. An example of the latter crime would be when the partners are hitting each other as one of them is driving a vehicle down the road. There is a risk of a collision that could injure or kill the children. Another example would be slamming a door so hard that glass shatters and falls on children nearby. Or, perhaps a child is struck accidentally during a hitting, kicking, slapping, and punching fight between the members of the dyad, or maybe one partner is pushed down and lands on an infant left on the couch. ${ }^{\text {l }}$

Data from the U.S. Census Bureau suggests children may live in $61-86 \%$ of domestically violent homes. ${ }^{\mathrm{m}}$ Coupled with the fact that domestic violence is often ongoing, and not a single incident, the chances are high that children in domestically violent homes have witnessed multiple DV occurrences. Even if the children didn't witness tonight's fight, they probably saw the one that occurred last week. For this reason then, one should expect the majority of police reports to identify and describe child endangerment charges, most likely over multiple incidents.

In order to document child exposure to domestic violence first responding officers must interview each child individually. Officers should also interview other members of the family such as grandparents, and also nonfamily who may reside in the home. Neighbors should be interviewed as well. From the information gained officers can then interview the victim, suspect, or coperpetrators, as the case may be, being in an informed position to challenge denials or minimizations. Doing so and citing specific knowledge about prior incidents that were previously denied may lead to victims being more forthcoming, and suspects making admissions of guilt. Officers would also need to take time to photograph the children, the home, and so forth.

Alcohol, drugs, intoxication, child abuse, and other crimes: Other charges may include being intoxicated on drugs or alcohol during the crime. ${ }^{\mathrm{n}}$ Relatedly, if the suspect is regularly intoxicated in the presence of children yet another charge can be added. ${ }^{\circ}$ Still other charges may be uncovered if a conduct order is located through a computer check and in some manner it has been violated, or if a check shows one or both combatants are on probation or parole, etc. It is also possible that other crime that is unrelated to DV will also be uncovered, such as drug sales, counterfeiting, child abuse, operation of an unlicensed daycare center, an unlicensed automotive repair shop being run out of the garage, and so forth.

\section{Other important FRPO actions}

There are a number of actions that, when taken by the first responding police officer, increase the inclusion of a variety of sentencing components. The first is to complete the investigation and submit a written report within

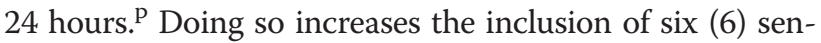
tencing components. Documenting the suspect's invocation of her/his 5th Amendment right positively influences nine (9) outcomes, making an arrest influences five (5), obtaining photographs influences three (3), identifying child victims influences three (3), and finding and listing additional witnesses influences three (3). Indirectly, one could possibly interpret the positive influence of a suspect's admission of guilt to the FRPO as being partially due to the rapport-building and interrogation skills of the officer. Admissions of guilt positively influence four (4) outcomes. As an examination of these relationships demonstrate, the thoroughness of the police report is quite important to the construction of the content of the post-conviction DV criminal sentence.

Interestingly, for the first time, another police action emerges as significant-one that only influences sentencing but not rates of prosecution and conviction: The 
word count of the police officer's written report. This is seen in two outcomes. For each additional word in the first responding police officer's written report, the likelihood of both probation and jail increase by about $.0475 \%$, meaning for an extra 500 words the percent increase is about $24 \%$, and an extra 1,000 words increases the chances by almost $50 \%{ }^{\mathrm{q}}$ This finding directly contradicts the conventional wisdom at the police department under study, where sergeants enforce a rule of brevity in report writing. As it turns out, officers who write longer DV reports are engaged in productive activity. A somewhat similar finding has been reported for the relationship between word counts in statements made by suspects, and by witnesses, and the truthfulness and accuracy of their statements to police (Vrij et al. 2007; Allison et al. 2006, etc.) From a policy perspective the operational direction of these findings to police supervisors is clear: Officers should not be constrained from efforts to write more thorough descriptions of DV crime.

\section{Variables pertaining to statements by the suspect, made to the FRPO}

Four types of interactions between police and suspect were examined, with three demonstrating a significant effect upon one or more outcomes. Perhaps the most interesting and unexpected finding is the strong relationship between a suspect specifically invoking her/his Fifth Amendment right to remain silent, and the increased likelihood a variety of different components will be included in the sentence. The mechanics of how this happens are not clear, but, it appears one or more of the parties involved in sentencing, that being the judge, prosecutor, and defense attorney-are influenced by the suspect's stated choice to be silent. This seems to contradict the spirit of a 1981 United States Supreme Court ruling, in Carter v. Kentucky (450 U.S. 288), in which the court established a particular jury instruction to be given in cases where the suspect invoked her/his 5 th Amendment right not to testify in court. Under these circumstances the jury is to be instructed not to interpret a defendant's silence as evidence of guilt. One might think the spirit of the Carter ruling would constrain judges and attorneys from making, apparently, a similar assumption of guilt towards a defendant who refused to give a statement to the police; if indeed that is the case.

There are at least two possible explanations for the Fifth Amendment effect. The first is that suspects who are actually guilty are more likely to invoke their right to silence, compared to suspects who are factually innocent; and thus perhaps, invocation of the right may actually be a marker of guilt. This explanation seems doubtful because all or nearly all of the suspects accused of domestic violence crime may actually be guilty, even if police are unable to document sufficient facts to cause a criminal case to be filed. Two reasons undergird this possibility. Meta-analytical examination of rates of false accusation of crime by police occur at a rate of between $0-3 \%$. This suggests nearly all persons accused of crime in police reports may actually be guilty (Zalman et al. 2008; Zalman, 2011). Also, police who knowingly or wantonly make false accusations could face criminal charges, and civil lawsuits-two seemingly strong inhibitions to making a false accusation. Thus, though triers of fact must assume innocence until guilt is proven (United States Supreme Court 1895), research scholars are not so-constrained in the assumptions they can make regarding actual guilt. Therefore, it seems reasonable to suspect that most individuals accused of domestic violence crime, by police, are actually guilty.

The second alternative explanation for the Fifth Amendment effect is qualitative in nature, an impression formed during the data collection phase of present work. Conversation with some members of the DV prosecution unit suggests that some prosecutors regard the invocation of one's 5th Amendment right as a marker of the suspect/defendant being "in a state of denial", meaning that (s)he is trying to subvert justice for the victim by not cooperating with investigating police. Some prosecutors seemed to take invocation cases personally, perhaps leading them to devote more prosecutorial energy. Regardless as to the cause(s) of the First Amendment effect, it expresses a significant positive influence upon multiple sentencing outcomes. That in turn sends a clear message to DV suspects: When police try to question you, invoke your Fifth Amendment right at your own peril.

\section{Demographics}

One would expect the court to be sex, gender, race, and culture-blind when sentencing convicted domestic violence offenders; and, anecdotally, it was observed that judges in the system under study seemed to make an effort to be that way. That doesn't mean, necessarily, that demographic differences are not seen, because they are; rather, this is to suggest they may not represent intentional bias from the bench. It is interesting to note that with the exception of two demographics that showed a positive influence, male and Asian, the remainder expressed a negative effect; that is, they reduced the likelihood of inclusion for some sentencing items.

Overall, race had little effect. In two categories, search waiver and an order not to annoy, threaten, harass, or strike the victim if the victim was Asian, the probability of inclusion in the sentence was increased. This may be related to the large number of violent Asian gangs in the city, with search waivers and also an extra order against violence and intimidation both possibly reflecting the defendant's known gang member status. In another 
category, an order not to commit the same or similar offense, if the victim was Black the likelihood of inclusion for one sentencing item, an order not to commit the same or similar offense again were diminished. The reasons for this are unclear. In two categories, search waiver and an order to pay restitution, if the victim was White the likelihood decreased. This may represent lower rates of criminal history, greater income, and higher rates of White couples staying together.

The major demographic finding is not unexpected: In six sentencing categories if the defendant is male, the likelihood of being given the measure increase significantly, those being: An order to pay restitution to the victim, a prohibition against ownership or possession of guns, an order to stay away from the victim, an order to attend a DV re-education course, and also probation and jail time. It is unclear why female defendants convicted of the same crimes would receive these six sentencing options significantly less often. Possibly, some are responsive to the specifics circumstances. For example, perhaps males are more likely to own guns, and thus are more likely to receive a specific prohibition against owning or possessing them. Also, males may be employed more often, or are paid more, and thus the order to pay restitution responds to that circumstance. What is less clear, and may show bias on the part of prosecutors who negotiate plea bargains, or judges who approve them, is why males receive increased jail time, increased rates of assignment to probation, and increased rates of assignment to a DV re-education course. It is also possible that prior DV or other criminal history may explain these differences; however, because criminal history was not measured in the present study, that alternative cannot be assessed. It is also possible that sex bias is in operation.

The other demographic finding of note is age, both for defendant and also victim. Between the two groups a reduction of use is seen across 10 sentencing options. It is important to avoid confusing this outcome with the DVAVPE trend. As used here, age is assessed for its correlation to sentencing outcomes, not the potential for recidivism. In their review of studies that examine sentencing leniency and age of defendant, (Steffenmeier et al. 1998) reported the same phenomenon; thus, the results of the present study confirm their finding of an age/leniency effect (ALE), which is an inverse relationship between age and the volume of content of a criminal sentence. The present work adds a new, unstudied dimension to the ALE by distinguishing between victim and defendant. Interestingly, the effect was seen to be stronger for the victim's age, correlating to reduced likelihood in six categories, compared to defendant's age, which correlated to four.

One possible explanation for the ALE is that the court must be aware, in some manner, of the DV-AVPE; after all, most of the defendants they see are young. Perhaps older defendants may incur lesser penalties because more of them may be seen as otherwise productive members of society, something Feder and Dugan call having a "stake in conformity" (2002). The same reason may explain the positive correlation between age of victim and leniency, at least in the cases where the victim and defendant remain together as a couple. Future work in this area could compare rates of leniency between couples that stay together, and those who separate. Perhaps the effect would be less strong in the latter group.

\section{Sentences not adhering to the law}

Ironically, judges in the jurisdiction under study regularly issue sentencing orders that disregard mandates of law. Section 1203.097 of the California Penal Code is clear in its requirements: One hundred percent (100\%) of all persons convicted of DV crime must attend a reeducation program, be put on three years probation, and perform community service, along with other requirements as well. In the jurisdiction under study judges did not order probation in almost a third of felony cases, ${ }^{r}$ and $19 \%$ of misdemeanor cases. Similarly, only half of the convicted persons for each type of DV crime were mandated to attend re-education programs. Finally, no convicted person was ordered to perform community service. These findings confirm the California State Attorney General's observation that judges do not always follow the law when sentencing persons convicted of DV crime (2005).

The present study was limited to collection of data in police and prosecution databases; as such, judges were not interviewed. However, bearing in mind that nearly all DV sentences are the product of negotiation between prosecutors and defense attorneys, the disregarding of sentencing mandates may not necessarily reflect judicial contempt. Indeed, qualitative observations made in a number of domestic violence courtrooms showed consistent and concerned engagement of many judges with the DV cases brought before them. Thus, alternative explanations should be considered, of which there are at least three.

First is the fact that, as already noted, nearly all criminal cases are resolved through plea bargaining. As such, sentencing deviations may more accurately reflect a deal worked out between prosecutors and defense attorneys more than the sentencing wisdom of a judge. Second and relatedly, in an era of shrinking judicial budgets, courts simply cannot afford to try many cases. Being economically indentured to the plea bargaining process would surely serve to constrain the range of a jurist's personal judgment. Judges may have to accept more negotiated sentences as a function of economic reality. Thirdly, as the results of the present study demonstrate, 
a number of antecedents also strongly influence the inclusion of the various sentencing components.

\section{What is the value of increasing the volume of the $d v$ criminal sentence?}

At least two answers can be given to the question. The first has already been discussed, and thus will merely be summarized here: Fundamentally, it is assumed an increase in the content volume of domestic violence sentences post criminal conviction will result in greater pressure being applied to the DV-AVPE, hopefully driving it downward significantly. The second reason is specific to victims of domestic violence, which includes children. Reducing DV recidivism is seen as a way to hopefully bring some relief to them. This second reason, described in more detail below, is because doing so may help to solve a long standing problem in criminal justice-how to drive down rates of domestic violence recidivism. This is the grail pursued by the present study, operationalized by application of a new form of criminological practice: Problem-solving criminology.

\section{Problem-solving, neutrality, and obligation}

Problem-solving criminology may depart from a more traditional, value-neutral approach used across a span of scientific disciplines to communicate empirical findings. Neutrality may be appropriate in physics and botany; however, when preventable suffering is described in one's data a moral imperative is believed to attach to one's work. So long as one is non-ideological, quantitative, and submitted to the process of falsification there seems to be room to identify validated methods that can reduce suffering in the population under study, and also to urge for their implementation. Accordingly then, right or wrong, with intention this paper tacks towards the goals of elevating rates of DV prosecution, raising rates of DV conviction, and also increasing the content of DV criminal sentences. Presenting validated and lawful ways these goals may well be accomplished is seen as an appropriate response to the moral imperative that has attached itself to the present work.

\section{Does increased sentencing impact rates of recidivism?}

As noted previously, the body of literature specific to the breadth of domestic violence sentencing is non-existent. A few articles examine a few sentencing options and their relationship to recidivism. Unfortunately however, most of these have limited generalizability and therefore limited utility because of substantial flaws. 'This is true for at least four reasons. First, many operationalize a sexist bias in the selection of research subjects, looking only at male batters who unidirectionally assault female victims. By doing so they ignore the other six human dyads that experience domestic violence, those being categorized according to foci of love and the direction of violence. ${ }^{t}$ Secondly, these same studies ignore the largest sub-category of domestic violence: Non-self defensive, heterosexual, mutual battering. A growing body of evidence, now numbering in the hundreds of studies indicates this category may constitute up to $60 \%$ of all DV (Straus 2008, 2010). ${ }^{\mathrm{u}}$ Third, ideological assumptions made in some of the papers, as suggested by word choices and sometimes openly admitted to, raise questions regarding the potential mapping of dogma onto findings. Finally, some of the studies suffer from poor design such that the reliability of their results is uncertain. Only a few studies meet design and neutrality criteria that permit their results can be relied upon to gain insight into the potential benefit of increased DV sentences.

The first is a 1998 study by Thistlethwaite, Wooldredge, \& Gibbs, who followed $\mathrm{N}=760$ male and female defendants for a year after they were arrested for domestic violence. They report a significant inverse relationship between severity of sentence and rates of recidivism. Severity was defined as an increasing presence of jail, probation, and fines in the sentence. Interestingly, it was not the length of of a jail sentence, or even the length of the term of probation that were found to be significant; rather, the effect was triggered by being given these sentencing options.

Wooldredge and Thistlethwaite (2002) followed $\mathrm{N}=3,110$ male and female suspects arrested for misdemeanor DV, for a two year period. Initially all were charged with DV by prosecutors. How the researchers defined the two year period is interesting. One group had their charges dropped or they were acquitted at trial. Their period of observation began the day of the disposition. The second group were convicted. Their two year period began the day they were released from their sentence, having served time in jail, or completed probation, and presumably completed a wide variety of other sentencing options that were not identified or measured in the study. Wooldredge and Thislethwaite report sentenced individuals had significantly lower rates of DV recidivism, though they didn't account for the aging process in their data. The researchers also found reduced recidivism in offenders sentenced to attend counseling so long as they had a stake in conformity. That was defined as higher levels of education, higher rates of employment, not needing public assistance, and living in the same residence at least five years.

Ventura and Davis (2005) followed $\mathrm{N}=1,982$ male and female defendants against whom a domestic violence criminal case was filed. They measured recidivism one year after case were either dismissed, or the defendant was convicted. Their results show conviction to be significantly associated with reduced recidivism. However, considering they measured the period in which the sentence was operationalized, what Ventura and Davis are 
believed to have actually measured is the cumulative effects of carried-out criminal DV sentences. Thus, their findings seem to indicate a significant inverse relationship between the sum of the effects of the operationalized criminal DV sentence and rates of DV recidivism. The researchers also report observing younger batterers to have higher rates of DV recidivism, a finding that is consistent with the data plot seen in Figure 2.

\section{Conclusions \& Recommendations}

\section{Re-evaluating studies that have not accounted for the} natural decline

It is possible that prior longitudinal studies may have introduced a substantial amount of Type II error into their results by having failed to account for the natural process of recidivism decay. We can calculate the approximate amount of Type II error using:

$$
\mathrm{PE}=\frac{\operatorname{Pct} \Delta_{\mathrm{STUDY}}}{\operatorname{Pct} \Delta_{\mathrm{STUDY}}-\mathrm{xb}} * 10^{2}
$$

where PE is the percentage of Type II error that may be present, $\mathrm{x}$ is the number of years or fractions of years the data represents, and $b$ is the coefficient of natural change according to sex (female $=2.56$, male $=3.13$ ).

For example, suppose a three year longitudinal study reports a $10 \%$ reduction in DV recidivism for both males and females, which they attribute to a particular treatment. Using Eq. 5 we calculate the potential amount of Type II error as $431 \%$ for females and $1639 \%$ for males. Of the $10 \%$ change in the female rate measured over three years, we know that about $7.68 \%$ is actually due to aging, meaning only $2.32 \%$, at most, would be attributable to the treatment. In the case of males, nearly all of the claimed effectiveness of treatment would actually be due to the natural process. Thus, as the example demonstrates, what may seem to be significant treatment result might not actually be when the natural process is accounted for.

It is also possible that studies that have failed to detect and account for the delayed maxima of male violence potential, as seen to occur around age 28 , may be at risk of both types of error. The rate of increase prior to about age 28 , and the rate of decrease after about age 28 would both need to be accounted for.

\section{Follow up that is indicated}

\section{What researchers can do}

The first thing that researchers can do to try to increase rates of prosecution, conviction, and the volume of DV sentences is to spend more time searching for, identifying, and studying a much larger set of pertinent phenomenon and their antecedents. A subset of this focus would be to identify antecedents that are susceptible to lawful manipulation.
It is hoped that more researchers will begin to engage in problem-solving criminology of the type that is demonstrated in this article and the last (Nelson, 2013).

Secondly, it is believed that researchers should take steps to examine the breadth of the human experience of domestic violence. We need broader studies that examine all seven forms of DV, not narrow studies whose subsets may be constrained by biased selection practices, and whose reports may have been submitted to ideological guidelines of interpretation. The imposition of a lens of dogma is seen to elevate the risk of mis-handling and/or mis-characterizing results. It is believed that researchers should resist the temptation be unduly influenced by historical ideologies that have not always fared well when they were subjected to the crucible of quantitative falsification. Better study design should result in more useful and generalizable findings related to the human problem of domestic violence.

Thirdly, in the domestic violence literature there seems to be an inordinate focus upon demographics. Undoubtedly, explaining the why of phenomenon is of fundamental importance. What seems to be in short supply are studies that validate the how-to of criminal justice best practices. If scholars want to do something about domestic violence then it is believed the focus of DV research should turn towards how-to studies that examine for best practices methods. It is believed much fruitful work can be accomplished in this research area because so little has been done in it so far.

\section{What first responding police officers can do}

Police officers should be encouraged to operationalize the six optional investigative techniques, and also to write thorough, detailed reports, being certain to note if the suspect invoked the 5th Amendment right to silence. Investigative thoroughness is more burdensome to the FRPO because it takes more time to knock on doors and interview neighbors; or to sequester each child individually and interview them, or to take photographs, or track down a departed suspect(s) so an arrest can be made, and so forth.

\section{What police sergeants can do}

Because of the natural temptation towards minimal investigation exists, the monitoring and instruction role of sergeants is therefore seen as essential if a commitment to thoroughly investigating every domestic violence crime is to actually put into routine practice. Sergeants can monitor the investigation in real time, stepping in to direct greater thoroughness when it is needed. However, the assumption shouldn't be made that sergeants will necessarily be willing to support thorough DV crime investigations as the new normal routine. Skogan notes many community policing projects have failed when they did not win the 
support of sergeants and other mid-level police managers who were called upon to insure officers operationalized them (Skogan 2008).

\section{What police chiefs and county sheriffs can do}

Unfortunately, poor policing of domestic violence crime does not merely originate at the level of the individual FRPO, or in small units under the leadership of a single sergeant who may either fail to demand investigative thoroughness, or who may subvert directions to do so. A comprehensive evaluation of the criminal justice response to domestic violence crime by the California State Attorney General (CA-SAG) found that entire police agencies were seen to put insufficient effort into DV crime investigation (CA-SAG 2005:54). Thus, the will-to and power to solve the problem of insufficient DV investigation probably resides at a level higher than the police agency. That noted, individual Chiefs and Sheriffs can lead the way to reform by adopting and enforcing zero tolerance policies for inadequate DV crime investigation.

\section{What legislatures can do}

As the last three sections indicated, leaving the choice to investigate thoroughly to the individual officer, enforcement to the individual sergeant, or even to entire police organizations may not solve the fundamental problem of FRPO's writing a short, single charge DV crime report. Thus, imposition of legal mandates with systems of efficient monitoring seem to be indicated. Using arrest as an example, it wasn't until laws were passed in the 1990's and early 2000's mandating arrest of DV suspects that police officers and police agencies began to do what they weren't doing optionally. After laws requiring arrest of DV suspects were implemented DV prosecution rates permanently increased by about $14 \%$ and conviction rates by about $5 \%$. This shows that rates of DV prosecution and conviction can be raised permanently by the right mandates (Garner \& Maxwell, 2009: Table 3).

Legislators are encouraged to mandate thorough DV investigations that operationalize the six actions validated as the DV investigation best practices model (Nelson, 2013). Further, the mandate should require officers to document efforts made to operationalize actions that were unfruitful. For example, if the FRPO reports no photographs were taken, (s)he should be required to explain the efforts put into attempting to photograph the victim(s), children, injuries, broken items, and the general crime scene. This type of accountability, coupled with periodic outside reviews whose quantitative results are reported to the legislature and the public may compel greater attention to the investigation of domestic violence crime. If funding to police agencies is tied to measures of performance, one would also expect improvement in the thoroughness of DV investigations.

\section{What legislatures and judges can do: eliminate a failed sentencing component}

Meta-analytical and U.S. government reports indicate that the re-education sentencing components such as the "Duluth" program are not effective in lowering rates of recidivism (National Institute of Justice 2003a, 2003b; Babcock et al. 2004; Feder \& Wilson 2005). Even if empirical studies were to demonstrate reduced rates of recidivism in treatment or re-education participants, over time, if those rates were significantly less than the natural rate of DV decline it is possible what they are actually measuring is an increase in recidivism for their participants. Clearly the possibility that re-education programs may increase rates of recidivism, and thus possibly cause more harm to children and adult victims of domestic violence crime bears additional study.

Legislatures should consider what some California judges are already doing: Eliminating the use of re-education programs in the domestic violence criminal sentence. Since no benefit can be demonstrated for these programs, and since re-analysis of program claims using Eq. 5 may confirm they actually raise rates of recidivism, and in contemplation of the best care of victims it seems that legislatures should either prohibit their further use, or at the least set up sufficient quantitative studies of their efficacy, studies whose design include the use of Eq. 5.

\section{What concerned citizens can do}

There are at least three actions that concerned citizens can operationalize in an effort to permanently raise rates of domestic violence prosecution and conviction, and thus also the volume of content of the DV sentence. First, they should probably conclude that change will occur when laws are passed, mandating thorough DV investigations by police every time. Thus, they should focus efforts on the creation and passing of bills that mandate implementation of the best practices DV investigation model (see Nelson, 2013). Second, citizens can hold politicians accountable for the level of support they give to bills that are mandate a zero tolerance policy for inadequate DV investigation, and how they voted. The internet has provided an inexpensive means by which citizens can document which politicians have supported DV investigation mandates, and which have not. Reminding politicians these are bills that protect child victims of DV may add extra pressure, because most politicians would probably want to avoid being accused of voting against protections for children. Finally, citizens can join police oversight boards in order to hold police agencies accountable for their domestic violence investigation practices. 


\section{Endnotes}

${ }^{\text {a }}$ This is calculated from data found in Table D-4, using $\mathrm{N}=91,938$ total cases, and $\mathrm{n}=89,635$ pleas of guilt.

${ }^{\mathrm{b}}$ The Blonigen article has an excellent, current, and detailed review of the literature on age and crime. It can be used as a reference guide.

${ }^{\mathrm{C}}$ These data are drawn from year 2000 Federal Bureau of Investigation arrest statistics for violent crime (2003, p. 6). The table provides 21 age increments, from age 12 and under to age 65 and over. Frequencies for each age are determined by $n / N$ where $n$ is the number of arrests for violent crime at a given age, and $\mathrm{N}$ is the total number of arrests for all time periods, for that sex. Use of this method permits between comparison of within group rate changes. This plot is not intended to demonstrate total counts of violence, by sex, per year of age. The mean difference of violence by males is about five times greater $($ mean $=5.30, \mathrm{sd}=1.37)$.

${ }^{d}$ The specific mathematics that underlie the calculation of $b$ remain to be discovered.

${ }^{\mathrm{e}}$ As noted by (Hartwig and Dearing 1979:12), visual inspection of graphs is a power analytical tool which should not be overlooked.

${ }^{\mathrm{f}}$ It is important to note that the additional step of subtracting one (1) from the product of $\exp ^{\beta}$ is required when converting a Beta value to a percent change value, rather than an odds ratio.

gThese data are drawn from a different subset of the larger data set from which the data used in the present article is also drawn. See Nelson (2013) for further on the data set from which this example is drawn.

${ }^{\mathrm{h}}$ These three variables were also used as outcomes during assessment of some explanatory variables.

${ }^{i}$ The one exception is the number of charges the defendant is convicted of. In the present study $98 \%$ of all convictions were negotiated through plea bargaining, and not established by trial; accordingly, one can reasonably suspect feedback loops that shape the number and type of charges for which a defendant is convicted. Thus, for this variable alone, a causal relationship is not assumed.

${ }^{j}$ These are the categories of violence as identified by the FBI, whose data was used to construct Figure 1. See p. 5 of the source publication for details (Federal Bureau of Investigation 2003).

${ }^{\mathrm{k}}$ There are specific periods of time in which a past crime can be prosecuted. Once that period has passed charges can no longer be filed and essentially the perpetrator has gotten away with committing the crime. Laws that limit the period of time in which criminal charges can be filed are called statutes of limitation. In the United States the statute of limitations for all crimes is at least one year. For some more serious crimes the statute of limitations is more than one year. In the case of murder there is no statute-it can be charged forever, until the perpetrator dies. The Rape Abuse and Incest National Network (RAINN) has devoted considerable effort to tracking statute of limitation laws in the U.S. Their data is accessible in an on-line searchable database found here: http://rainn.org.

${ }^{\mathrm{l}}$ These are actual incidents investigated by the author when he was a police officer.

${ }^{\mathrm{m}}$ The National Longitudinal Study of Adolescent Health ( $\mathrm{N}=11,370$, see Whitaker, Haileyesus et al. 2007) shows about $24 \%$ of $18-28$ year olds are involved in one or more domestic violence incidents in a given year. Data from the U.S. Census Bureau shows children are present in about $61 \%$ of the homes where adults are ages $20-24$, increasing to $86 \%$ by the time adults are in the 35-39 year old range (United States Census Bureau 2003). We don't know for certain if the frequency of the presence of children is higher or lower in domestically violent homes, so, we must assume it is about the same rate as in the general U.S. population.

${ }^{\mathrm{n}}$ There are a variety of charges that describe alcohol or drug related offenses in California.

${ }^{\circ} \mathrm{CPC} \$ 273 \mathrm{~g}$.

PThe period measured was 10 days; however, one must contemplate the process that follow submission of the written report, by the FRPO. From there, at the agency under study, it is reviewed by the patrol sergeant, the domestic violence unit sergeant, a civilian checks it for technical accuracy and completeness, and sometimes a senior officer in a special unit also reviews the report. This can take several days or more. Thus, the obligation is upon the FRPO to get the review process started as soon as possible by submitting her/his written report the same day.

${ }^{\mathrm{q}}$ Of course, one probably cannot uncouple the entangled relationship between length of report, as measured in words, and the number of crimes that are alleged in it.

${ }^{\mathrm{r}}$ As noted previously, some of these data may be accounted for by the $14 \%$ of cases where the convicted person was sentenced to a term in prison.

${ }^{\mathrm{s}}$ Garner and Maxwell meta-analytically reviewed $\mathrm{N}=32$ studies that describe, in some fashion, DV sentencing (Garner and Maxwell 2010). Their comprehensive article can be used as a topical guide to the prior literature on the subject. Each study is critically evaluated for design, with Garner and Maxwell "lament(ing)" the lack of methodological rigor that is evident in many of them, noting "Our assessment is that, as a body of research, it is difficult to use these studies to support or oppose a particular policy or to test a particular hypothesis" (page 66).

${ }^{\mathrm{t}}$ All seven categories can be shown by using $\mathrm{M}=$ male, $\mathrm{F}=$ female, and arrows to indicate the direction of violence. Single headed arrows (e.g., $<=$ or $=>$ ) show unidirectional violence whereas a double-headed arrow (e.g., <=>) shows 
violence that is non-self defensive and bidirectional. The seven categories are: $\mathrm{M}=>\mathrm{M}, \mathrm{M}<=>\mathrm{M}, \mathrm{F}=>\mathrm{F}, \mathrm{F}<=>\mathrm{F}$, $\mathrm{M}=>\mathrm{F}, \mathrm{M}<=\mathrm{F}$, and $\mathrm{M}<=>\mathrm{F}$.

${ }^{\mathrm{u}}$ Both of these articles should be consulted as a reference guide to well-designed quantitative studies.

\section{Competing interests}

The author declares that he has no competing interests.

Received: 14 March 2013 Accepted: 13 November 2013 Published: 17 December 2013

\section{References}

Allison, M, Brimscomb, CAE, Hunter, MA, \& Kadlec, H. (2006). Young and older adult eyewitnesses' use of narrative features in testimony. Disease Processes, 41(3), 289-314

Alschuler, AW. (1979). Plea bargaining and its history. Columbia Law Review, 79(1), 1-43.

Babcock, JC, Green, CE, \& Robie, C. (2004). Does batterers' treatment work? A meta-analytic review of domestic violence treatment. Clinical Psychology Review, 23(8), 1023-53

Blonigen, DM. (2010). Explaining the relationship between age and crime: contributions from the developmental literature on personality. Clinical Psychology Review, 30(1), 89-100.

California Research Bureau. (2003). Adult parole and probation in California. Sacramento, CA: California Research Bureau.

Bureau of Justice Statistics. (2008). Special report: State court processing of domestic violence cases. Washington, D.C.: United States Department of Justice.

Chiricos, TG, \& Waldo, GP. (1975). Socioeconomic status and criminal sentencing an empirical assessment of a conflict proposition. American Sociological Review, 40(6), 753-72

Corvo, K, Dutton, D, \& Chen, WY. (2008). Towards evidence-based practice with domestic violence perpetrators. Journal of Aggression, Maltreatment \& Trauma, 16(2), 111-30

Diviney, CL, Parekh, A, \& Olson, LM. (2008). Outcomes of civil protective orders: results from one state. Journal of Interpersonal Violence, 28(7), 1209-21.

Dunford, FW. (2000). The San Diego Navy experiment: an assessment of interventions for men who assault their wives. Journal of Consulting and Clinical Psychology, 68(3), 468-76.

Dutton, DG. (2005). Domestic abuse assessment in child custody disputes: beware the domestic violence research paradigm. Journal of Child Custody, 2(4), 23-42.

Dutton, DG, \& Corvo, K. (2006). Transforming a flawed policy: a call to revise psychology and science in domestic violence research and practice. Aggression and Violent Behavior, 11(5), 457-83.

Farrington, DP. (1986). Age and crime. Crime and Justice, 7, 189-250.

Feder, L, \& Dugan, L. (2002). A test of the efficacy of court-mandated counseling for domestic violence offenders: the Broward experiment. Justice Quarterly, 19 (2), 343-75.

Feder, L, \& Wilson, DB. (2005). A meta-analytic review of court-mandated batterer intervention programs: Can courts affect abusers' behavior? Journal of Experimental Criminology, 1(2), 239-62.

Federal Bureau of Investigation. (2003). Age-specific arrest rates and race-specific arrest rates for selected offenses 1993-2001, Violent crime, age-specific arrest rates by sex, year 2000. Washington, D.C.: United States Department of Justice.

Felson, RB, Ackerman, JM \& Gallagher, CA. (2005). Police intervention and the repeat of domestic assault. Criminology, 43(3), 563-88.

Garner, JH, \& Maxwell, CD. (2009). Prosecution and conviction rates for intimate partner violence. Criminal Justice Review, 34(1), 44-79.

Garner, JH, \& Maxwell, CD. (2010). The crime control effects of criminal sanctions for intimate partner violence (Final report to National Institute of Justice). Retrieved from https://www.ncjrs.gov/pdffiles1/nij/grants/236959.pdf.

General, CSA. (2005). Keeping the promise: victim safety and batterer accountability. Sacramento, CA: California Department of Justice.

Hartwig, F, \& Dearing, BE. (1979). Exploring data analysis. Newbury Park, CA: Sage

Hirschi, T, \& Gottfredson, M. (1983). Age and the explanation of crime. AJS, 89(3), 552-84.

Illinois Criminal Justice Information Authority. (2002). Research and program evaluation in Illinois: Studies on drug abuse and violent crime. Chicago, IL: Illinois Criminal Justice Information Authority.
Kingsnorth, R, Lopez, J, Wentworth, J, \& Cummings, D. (1998). Adult sexual assault: the role of racial/ethnic composition in prosecution and sentencing. Journal of Criminology Justice, 26(5), 359-71.

National Institute of Justice. (2003a). Do batterer intervention programs work? Washington, D.C.: United States Department of Justice.

National Institute of Justice. (2003b). Batterer intervention programs: Where do we go from here? Washington, D.C.: United States Department of Justice.

Nelson, EL. (2013). Police controlled antecedents which significantly elevate prosecution and conviction rates in domestic violence cases. Criminology \& Crim Justice, 13(5), 526-51. Prepublished November 5, 2012, DOI: $10.1177 /$ 1748895812462594, http://cri.sagepub.com/content/13/5/526

O'Leary, KD, Barling, J, Arias, I, \& Rosenbaum, A. (1989). Prevalence and stability of physical aggression between spouses: a longitudinal analysis. Journal of Consulting and Clinical Psychology, 57(2), 263-8.

Skogan, WG. (2008). Why Reforms Fail. Policing \& Society, 18(1), 23-34

Sourcebook of Criminal Justice Statistics. (2002). In K Maguire (Ed.), Felony convictions in state courts: Table 5.46.2002. Retrieved from www.albany.edu/ sourcebook/pdf/t5462002.pdf.

Sourcebook of Criminal Justice Statistics. (2004). In K Maguire (Ed.), Percent distribution of felony convictions in state courts: Table 5.46.2004. Retrieved from www.albany.edu/sourcebook/pdf/t5462004.pdf.

Steffensmeier, D, Ulmer, J, \& Kramer, J. (1998). The interaction of race, gender, and age in criminal sentencing: the punishment cost of being young, Black, and male. Criminology, 36(4), 763-98.

Straus, MA. (2008). Dominance and symmetry in partner violence by male and female university students in 32 nations. Child Youth Service Review, 30(3), 252-75.

Straus, MA. (2010). Thirty years of denying the evidence on gender symmetry in partner violence: Implications for prevention and treatment. Partner Abuse, 1 (3), 332-62.

Straus, MA, Gelles, RJ, \& Steinmetz, SK. (1980). Behind closed doors: violence in the American Family. New York: Anchor Books.

Tjaden, P, \& Thoennes, N. (2000). Prevalence and consequences of male-to-female and female-to-male intimate partner violence as measured by the National Violence against Women survey. Violence Against Women, 6(2), 142-61.

Ulmer, JT, \& Johnson, B. (2006). Sentencing in context: a multilevel analysis. Criminology, 42(1), 137-77.

United States Census Bureau. (2003). Table F1 - Family households by type, age of own children, age of family members, and age, race, and Hispanic origin of householder. Retrieved from http://www.census.gov/hhes/socdemo/children/ data/cps/2002/tabF1-all.pdf.

United States Courts. (2011). Judicial business of the United States Courts: 2011 annual report of the director. Washington, D.C.: USC.

United States Supreme Court. (1895). Coffin v. United States. 156 U.S. 432.

United States Supreme Court. (1981). Carter v. Kentucky. 450 US 288.

Ventura, LA, \& Davis, G. (2005). Domestic violence: Court case conviction and recidivism. Violence Against Women, 11(2), 255-77.

Vrij, A, Mann, S, Kristen, S, \& Fisher, RP. (2007). Cues to deception and ability to detect lies as a function of police interview styles. Law and Human Behavior, 31(5), 499-518.

Whitaker, DJ, Baker, CK, \& Arias, I. (2007a). Interventions to prevent intimate partner violence. In LS Doll, SE Bonzo, DA Sleet, \& JA Mercy (Eds.), Handbook of Injury and Violence Prevention (pp. 203-21). NY: Springer.

Whitaker, DJ, Haileyesus, T, Swahn, M, \& Saltzman, LS. (2007b). Differences in frequency of violence and reported injury between relationships with reciprocal and nonreciprocal intimate partner violence. American Journal of Public Health, 97(5), 941-7.

Wooldredge, J, \& Thistlethwaite, A. (2002). Reconsidering domestic violence recidivism: conditioned effects of legal controls by individual and aggregate levels of stake in conformity. Journal of Quantitative Criminology, 18(1), 45-70.

Wooldredge, J, \& Thistlethwaite, A. (2006). Bilevel disparities in court dispositions for intimate assault. Criminology, 42(2), 417-56.

Zalman, M. (2011). Qualitatively estimating the incidence of wrongful convictions-a postscript (Unpublished meta-analytical, topical anthology). Retrieved from http://works.bepress.com/marvin_zalman/1.

Zalman, M, Smith, B, \& Kiger, A. (2008). Officials' estimates of the incidence of 'actual innocence' convictions. Justice Quarterly, 25(1), 72-100.

doi:10.1186/2193-7680-2-9

Cite this article as: Nelson: Domestic violence sentencing: coefficient to a natural process that already reduces recidivism simply as a function of aging. Crime Science 2013 2:9. 